OPEN ACCESS

Edited by:

Patrizia d'Ettorre,

Université Paris 13, France

Reviewed by:

Katja Hoedjes,

Université de Lausanne, Switzerland Alessandro Cini

University College London,

United Kingdom

*Correspondence:

Magdalena M. Mair magdalena.mair@ur.de

Specialty section:

This article was submitted to

Chemical Ecology,

a section of the journal

Frontiers in Ecology and Evolution

Received: 24 February 2019 Accepted: 08 May 2019

Published: 24 May 2019

Citation:

Mair MM and Ruther J (2019) Chemical Ecology of the Parasitoid Wasp Genus Nasonia (Hymenoptera,

Pteromalidae).

Front. Ecol. Evol. 7:184

doi: 10.3389/fevo.2019.00184

\section{Chemical Ecology of the Parasitoid Wasp Genus Nasonia (Hymenoptera, Pteromalidae)}

\author{
Magdalena M. Mair* and Joachim Ruther \\ Institute of Zoology, University of Regensburg, Regensburg, Germany
}

The use of chemical cues and signals is essential for communication in insects. Wasps of the genus Nasonia (Hymenoptera, Pteromalidae) are gregarious parasitoids that lay their eggs into puparia of cyclorrhaphous flies. During their life cycle, various kinds of semiochemicals are used: (1) a male abdominal sex pheromone that attracts females and induces site fidelity in males, (2) a female-derived contact sex pheromone eliciting courtship behavior in males, (3) an oral male aphrodisiac eliciting receptivity signaling in females and causing a switch in the females' olfactory preferences, (4) chemicals derived from host habitat and host puparia used in olfactory host finding by female wasps, and (5) chemicals used by females to assess the quality and parasitization status of potential hosts. We review the literature on the chemical ecology of Nasonia spp. following the wasps' life cycle from emergence to oviposition. We depict biosynthetic pathways where available, discuss ecological implications, highlight differences among Nasonia species, summarize insights into their olfactory perception and associative learning abilities, and point out gaps in our understanding of the chemical ecology of these parasitoids to be addressed in future studies.

Keywords: biosynthesis, chemical communication, jewel wasp, life cycle, olfactory perception, parasitic wasp, pheromones, semiochemicals

\section{INTRODUCTION}

Chemicals are highly important to insect life enabling them to locate food and prey, to find, recognize and evaluate potential mating partners, to mediate the complex interactions in societies as well as to avoid natural enemies and suboptimal living conditions (Cardé and Baker, 1984; Symonds and Elgar, 2008; Wyatt, 2014). Even though other sensory stimuli such as visual and tactile cues are also employed by insects, chemicals often predominate in communication processes in several stages of the insects' life cycles. Since the identification of bombykol, the sex pheromone used by females of the silkworm moth Bombyx mori for long-range attraction of males (Butenandt et al., 1959), and the following establishment of the field of chemical ecology in the early 1960s, particular focus has been laid, among other topics, on the identification of chemical cues and signals used by insects to find mating partners and locate adequate foraging, and oviposition sites (Greenfield, 1981; Cardé and Baker, 1984; Renwick, 1989; Landolt, 1997; Pichersky and Gershenzon, 2002; Wyatt, 2014). Setting out for a specific destination (e.g., a mating site or oviposition site) in an often complex environment usually necessitates different stages of searching behavior. This includes the location of an adequate habitat using long-range volatiles and narrowing down the search to ever smaller spatial scales until finally making use of non-volatile 
substances to recognize mating partners or assess the quality of a food item or host by direct contact (Vinson, 1976). On the long range, the process of mate finding often involves the release of highly volatile sex pheromones by one sex and the attraction to these pheromones by individuals of the other sex (Greenfield, 1981). On the short range, males usually recognize females based on chemicals distributed over the females' cuticle (Lockey, 1988; Blomquist and Bagnères, 2010) and courtship frequently involves the transfer of a species-specific sex pheromone which allows females to assess not only the species of the courting male but also its quality (Birch and Hefetz, 1987; Scott et al., 1988).

In parasitic wasps, hymenopteran insects developing in or on different life stages of other arthropods, chemical cues and signals are used in a plethora of different situations. For mate finding, some species rely on volatile aggregation pheromones released by the aggregating wasps (e.g., in Barchymeria intermedia and B. lasus, Mohamed and Coppel, 1987). In other species, hostassociated volatile cues are attractive from a distance for both sexes thus enabling encounters of potential mates at these host patches (e.g., alarm pheromones produced by host-associated mites, Ruther and Steidle, 2000; or herbivore-induced plant volatiles, Xu et al., 2016; Xu and Turlings, 2018). Mostly, however, individuals of the opposite sex are attracted directly via volatile sex pheromones released by either females (Quicke, 1997; Ruther, 2013) or less frequently males (e.g., Melittobia digitata, Cônsoli et al., 2002; or Nasonia vitripennis, Ruther et al., 2007). At mating sites, intraspecific competition for mates sometimes involves the application of territorial markings by males (e.g., Urolepis rufipes, Cooper and King, 2015; N. vitripennis, Mair and Ruther, 2018). During encounters, female-derived cuticular lipids elicit courtship behavior in males (e.g., Roptrocerus xylophagorum, Sullivan, 2002) and in some species, courting males transfer an aphrodisiac from their antennal (e.g., Leptopilina spp., Weiss et al., 2015) or oral (e.g., N. vitripennis, Ruther et al., 2010) glands to the female's antennae. After mating, females typically use host-associated cues such as host pheromones or herbivoreinduced plant volatiles to locate adequate hosts (Vinson, 1976; Steidle and van Loon, 2002; Fatouros et al., 2008; Dicke, 2009; Turlings and Erb, 2018). At oviposition sites, females of some species have been found to make use of marking pheromones to avoid competition with other females (e.g., in Epidinocarcis lopezi, van Dijken et al., 1992; Nufio and Papaj, 2001), and in other species, females avoid aggression by releasing appeasement pheromones after having lost disputes with "owners" of already paralyzed hosts (e.g., Goniozus legneri, Goubault et al., 2006).

For decades, Nasonia vitripennis has served as a model for the study of parasitic wasp behavior (Whiting, 1967; van den Assem, 1986) and has since developed into a model in various other fields of biological research (Gadau et al., 2008; Werren and Loehlin, 2009; Werren et al., 2010; Schurmann et al., 2012; Ruther, 2013; Groothuis and Smid, 2017; Tappert et al., 2017). The rather recent identification of the three other Nasonia species (Darling and Werren, 1990; Raychoudhury et al., 2010a) now opens up the opportunity to switch from merely mechanistic studies of chemical ecology that identify the chemical signals and cues used in different contexts of intraspecific interactions and interactions between wasps and hosts, to comparative and

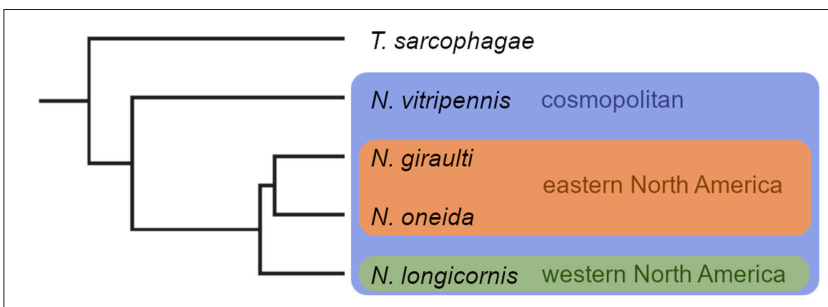

FIGURE 1 | Phylogenetic relationships and distribution of the four Nasonia species. N. vitripennis is cosmopolitan and occurs in sympatry with all other Nasonia species. N. longicornis is allopatric to N. giraulti and N. oneida. Phylogenetic tree originally published in Niehuis et al. (2013).

evolutionary studies that investigate chemical signal evolution and its consequences on interspecific interactions and sympatry. Nasonia wasps are easy to breed in the lab, easy to handle and due to their phylogenetic species structure and distribution pattern (differently related species occurring in sympatry and allopatry; Figure 1) form an exceptional model system for the study of the evolution of species-specific chemical communication and other reproductive isolation mechanisms. In particular, the combination of closely related species occurring in allopatry and less closely related species occurring in sympatry allows the differentiation between species characteristics resulting from phylogenetic relatedness and those that have been shaped by natural selection on unfit hybrids. Furthermore, the availability of the whole genome sequences (Werren et al., 2010) and the growing molecular toolbox for the Nasonia species (Lynch and Desplan, 2006; Lynch, 2015; Li et al., 2017) open up valuable opportunities to investigate biosynthetic pathways in detail and get new insights into insect chemical perception in general, both of which are fundamental for the understanding of the evolutionary processes shaping chemical communication in nature.

\section{THE GENUS NASONIA}

Wasps of the genus Nasonia (Hymenoptera, Pteromalidae) are parasitoids of pupae of various cyclorrhaphous flies (Diptera) found in nests of hole-breeding birds and on rotting carcasses (Darling and Werren, 1990; Raychoudhury et al., 2010a). The wasps are ectoparasitic and lay their eggs onto the surface of the fly pupa inside the fly puparium. Larvae feed on the host from the outside of the host body, pupate inside the host puparium and emerge from the puparium after eclosion. Nasonia wasps are gregarious, i.e., females lay more than one egg per host, and frequently several females lay their eggs into the same fly puparium (Grillenberger et al., 2008). Courtship and copulation happen at the natal host patch after emergence and females disperse after mating (King et al., 2000; Grillenberger et al., 2008; Ruther et al., 2014).

The genus Nasonia consists of four species. Nasonia vitripennis (Walker, 1836) $(N v)$, the species most intensely studied, is cosmopolitan and occurs sympatrically with all other Nasonia species (Raychoudhury et al., 2010b; Figure 1). Nasonia 
longicornis (Darling and Werren, 1990) (Nl) inhabits western North America, whereas N. giraulti (Darling and Werren, 1990) $(\mathrm{Ng})$ is restricted to eastern North America, and $\mathrm{N}$. oneida (Raychoudhury et al., 2010a) (No) is merely known from two locations in New York State, co-occurring with $\mathrm{Ng}$ and $N v$. Sympatric Nasonia species are frequently found on the same host patch and may even develop in microsympatry, i.e., within the same host individual (Darling and Werren, 1990; Grillenberger et al., 2009b; Raychoudhury et al., 2010a,b). In the natural environment, it is therefore likely that adult females and males of two sympatric species encounter and interfere on shared host patches. All Nasonia species, except for the species pair $\mathrm{Ng} / \mathrm{No}$, are reproductively isolated by Wolbachia-induced cytoplasmic incompatibility resulting in paternal chromosome loss after fertilization with heterospecific sperm (Breeuwer and Werren, 1990; Bordenstein et al., 2001). Females having mated with heterospecific males are not able to produce hybrid offspring. Instead, because Nasonia, like all hymenopterans, are haplodiploid, eggs fertilized by heterospecific sperm either die or develop into male offspring similar to unfertilized eggs (Breeuwer and Werren, 1990; Tram et al., 2006). As females of Nasonia usually mate only once during their lifetime, interspecific copulations are particularly costly for them (Liou and Price, 1994). Mechanisms involving adaptations in chemical communication have therefore evolved between Nasonia species to avoid and counteract the risks and costs of copulating with the wrong partner (e.g., Giesbers et al., 2013; Ruther et al., 2014).

The chemical communication system, particularly that of $N v$, is one of the best understood in insects. Studies on semiochemicals used by $N v$ have revealed pheromones and allelochemicals which are highly important for the wasps in almost all stages of their life: males use sex pheromones to scent mark territories and arrest females after emergence from the host (e.g., Ruther et al., 2007). They use female-derived contact sex pheromones to recognize potential mates (e.g., Steiner et al., 2006). During courtship, the male mounts the female and performs specific courtship movements coupled with the transfer of an aphrodisiac from the male's cephalic glands to the female's antennae to induce female receptivity (e.g., van den Assem et al., 1980b). After mating, females use host habitat cues to locate new host patches (e.g., Frederickx et al., 2013) and are able to assess host quality and the status of pre-parasitization by other females through chemical inspection with their ovipositors (e.g., King and Rafai, 1970; Blaul and Ruther, 2011; for a summary of the semiochemicals used in Nasonia see Table 1 and Figure 2).

In this article, we review literature on the chemical ecology of all four Nasonia species following the wasps' life cycle from emergence to oviposition (Figure 2). Focus is laid on chemical stimuli used by the wasps at different stages of their lives (Table 1) including, where available, information on biosynthetic pathways and ecological implications. Recent studies have revealed that the different Nasonia species differ in far more aspects of chemical communication and behavioral strategies than previously thought (Leonard and Boake, 2006; Niehuis et al., 2013; Ruther et al., 2014; Giesbers et al., 2016; Mair et al., 2017; Mair and Ruther, 2018). After discussing information available for $N v$, differences to the other three Nasonia species are thus highlighted where they are known. In addition, we give a short overview about what is known about the wasps' olfactory associative learning abilities and olfactory perception, including antennal morphology, sensory sensillae, and the genetic basis of chemosensory receptors and odorant binding proteins.

\section{Territoriality and Mate Acquisition-The Male Abdominal Sex Pheromone Behavioral Strategies of $N$. vitripennis Males}

Males of $N v$ emerge protandrously, i.e., they mostly emerge from the host prior to females by chewing an emergence hole into the fly puparium [Giesbers et al., 2016; Mair and Ruther, 2018; Figure 2(1)]. The first male often emerges several hours earlier than the following males and builds up a territory on the host which is defended aggressively against all other males emerging later or intruding from nearby hosts (van den Assem et al., 1980a; van den Assem, 1986; Leonard and Boake, 2006; Mair and Ruther, 2018). Subordinate males stay close to the territory and interfere with the territorial male regularly by challenging its position on the host. Although the territorial male is often the largest male in a group, experience (i.e., having experienced being in the territorial position and winning aggressive interactions) is more important than body size for the outcome of such malemale contests (Mair and Ruther, 2018). The territorial structure of a group can persist over longer time periods, but territoriality becomes increasingly unstable with increasing group size, finally resulting in scramble competition for females emerging from the host later (van den Assem et al., 1980a). Although this needs further investigations, group dynamics likely become more complex when several hosts occur in close proximity on a host patch giving territorial males the opportunity to enlarge their territory to include adjacent hosts and allowing subordinate males to potentially become territorial on hosts from which wasps have not yet emerged (van den Assem et al., 1980a; but see also Mair and Ruther, 2018). Emerging females are mounted and courted by the first male they encounter. By dominating the position on the host from which females are about to emerge, a territorial male should thus get prioritized access to copulations with females. However, observations under seminatural conditions have been unsuccessful in demonstrating a fitness benefit for territorial males over subordinate males in the lab (Mair and Ruther, 2018). In contrast to territorial males, subordinate males gain copulation opportunities by following an alternative reproductive strategy (Mair and Ruther, 2018). They frequently mount the female together with the territorial male, position themselves on the female's abdomen, sneak in when the female signals receptivity and copulate with the female instead of the courting territorial male. In addition, when two or more females emerge in a quick succession, it may happen that the territorial male is still occupied with courting the first female when the second female emerges, giving nearby subordinate males the opportunity to court and mate with the female themselves (Mair and Ruther, 2018). 


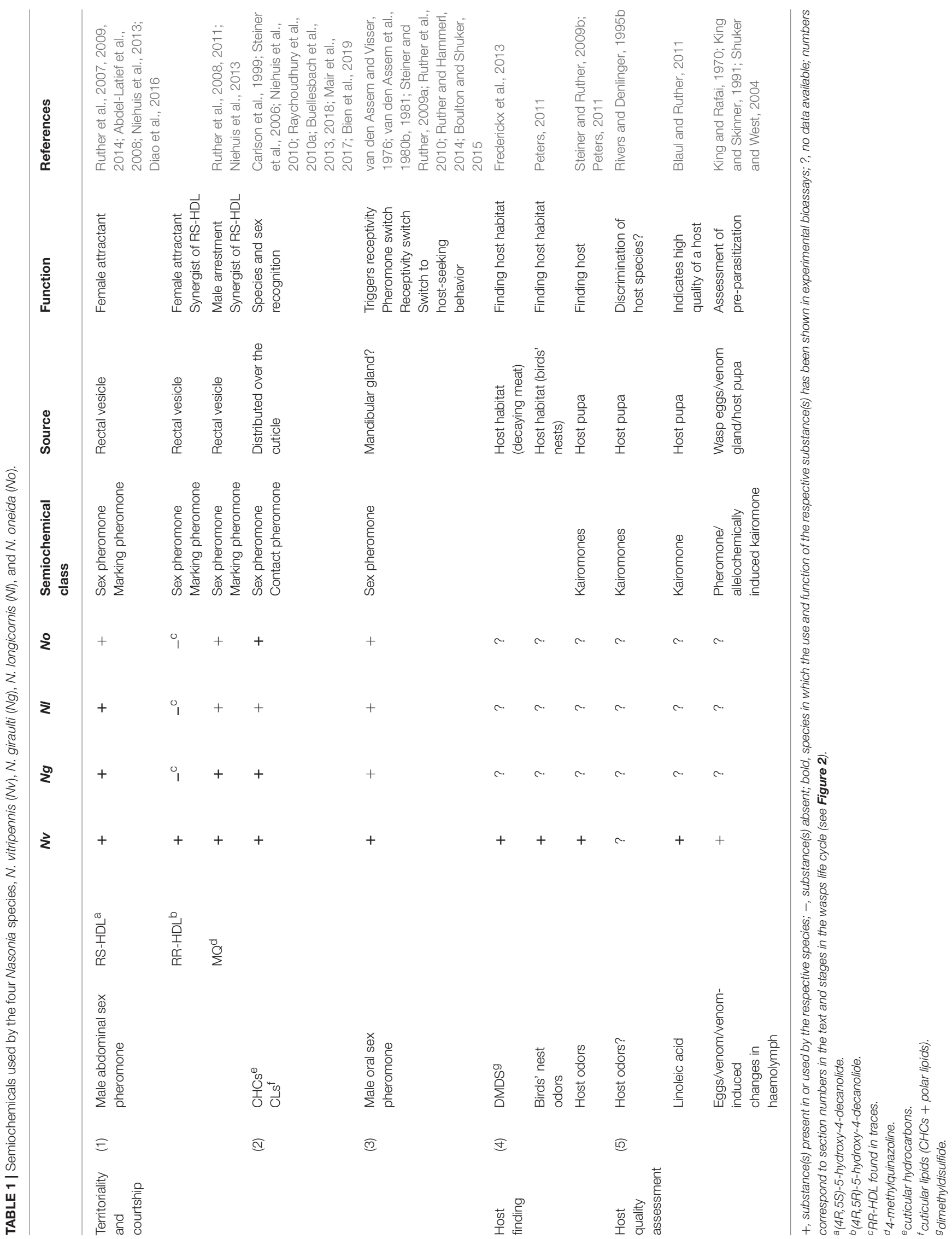




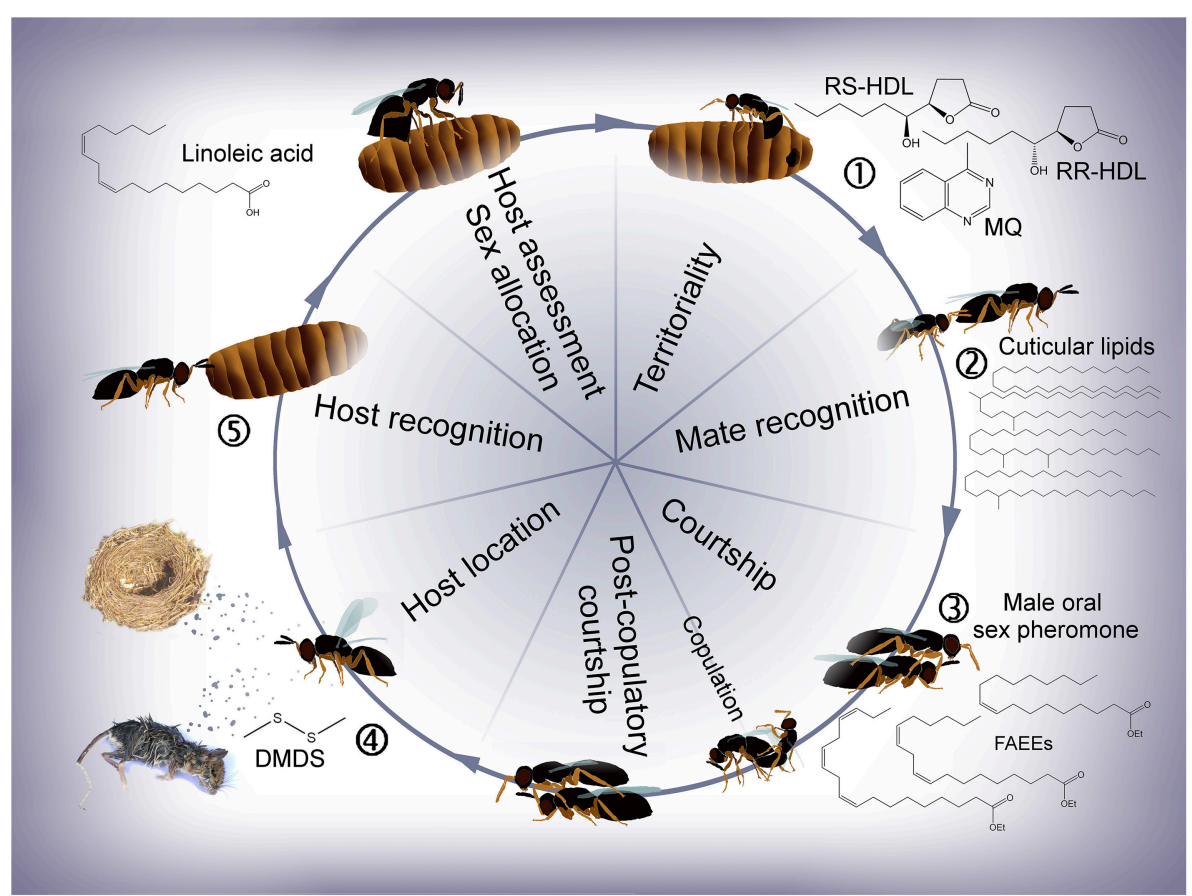

FIGURE 2 | Life cycle of Nasonia with emphasis on the different stages at which semiochemicals are involved. (1) Males apply an abdominal sex pheromone to the natal host and its surroundings to attract and arrest emerging females. (2) Males recognize females based on the females' cuticular hydrocarbons (CHCs, N. vitripennis) or cuticular lipids (CLs, = cuticular hydrocarbons + polar lipids, $N$. giraulti). (3) During courtship, a male oral sex pheromone is transferred to the female's antennae, females discriminate between conspecific and heterospecific mating partners and post-copulatory courtship induces a switch in the females' receptivity. (4) Females find new hosts based on olfactory cues. (5) Chemical stimuli are most likely involved during host recognition, host assessment and sex allocation (according to local mate competition theory). RR-HDL, (4R,5R)-5-hydroxy-4-decanolide; RS-HDL, (4R,5S)-5-hydroxy-4-decanolide; MQ, 4-methylquinazoline; FAEEs, fatty acid ethyl esters; DMDS, dimethyldisulphide.

Territorial Markings as Honest Signals of Male Quality Territoriality in $N v$ is accompanied by the application of pheromonal scent marks deposited by the territorial male on the surface of the host and areas nearby by performing dapping and streaking movements with its abdomen over the substrate, a behavior termed "abdomen dipping" (Barrass, 1969; Steiner and Ruther, 2009a; Ruther et al., 2011; Mair and Ruther, 2018). Marking behavior is intensified after contact to females and exhibited particularly often after successful copulation (van den Assem, 1986; Steiner and Ruther, 2009a). Territorial males show marking behavior more often than subordinate males (Mair and Ruther, 2018). Nevertheless, subordinate males exhibit marking behavior outside the central territorial area, likely at spots where they have previously encountered and eventually copulated with a female (Steiner and Ruther, 2009a; Mair and Ruther, 2018). The pheromonal markings are highly attractive for both females (virgin) and males, but males do not distinguish between their own markings and those laid by their competitors (van den Assem, 1986; Ruther et al., 2011). By eliciting site fidelity in both sexes, the pheromone prevents virgin females from moving away from the host after emergence and enables males to locate spots where females have been encountered before, either by themselves or by other males. Once deposited, the pheromone markings are attractive for ca. $2-3 \mathrm{~h}$ exceeding by far the usual time gap of $<50$ min between two consecutive emergences (Steiner and Ruther, 2009a; Mair and Ruther, 2018). A chemical basis for the attractiveness of the markings has been suggested already in 1980 (van den Assem et al., 1980b). The components of the abdominal marking pheromone have been identified as the two stereoisomers $(4 R, 5 S)$ - and $(4 R, 5 R)$-5-hydroxy-4decanolide (RS-HDL and RR-HDL, respectively) and the minor pheromonal component 4-methylquinazoline [MQ; Ruther et al., 2007, 2008, 2011; Steiner and Ruther, 2009b; Table 1(1)]. All three components are synthesized in the male rectal vesicle and are absent in females (Abdel-Latief et al., 2008). Males are attracted only by MQ whereas RS-HDL and RR-HDL do not elicit any specific behavioral responses (Ruther et al., 2011). In contrast, $N v$ females are attracted by RS-HDL alone which is synergized by both RR-HDL and MQ (Ruther et al., 2007, 2008; Steiner and Ruther, 2009a; Niehuis et al., 2013). In bioassays, the strongest attraction of females has been observed when all three components were presented together (Niehuis et al., 2013). In addition, the pheromone response of females is dose dependent with females preferring higher deposited amounts over lower ones (Ruther et al., 2009; Blaul and Ruther, 2011). After copulation, however, females are no longer attracted to the abdominal sex pheromone, become restless instead and 
switch to host-seeking behavior (Ruther et al., 2007, 2010, 2014; Steiner and Ruther, 2009b).

RS- and RR-HDL occur typically in the rectal vesicle at a 2:1 ratio and sex pheromone titers as well as the amount of pheromone actually deposited by males are associated with male body size and with male mating history (Ruther et al., 2009; Blaul and Ruther, 2012). Larger males produce and deposit more pheromone (up to $1 \mu \mathrm{g}$ total HDL) than smaller males $(<0.5$ $\mu \mathrm{g}$ total HDL; Blaul and Ruther, 2012), and male pheromone titers decrease with repeated marking activity following after each copulation (more than $60 \%$ reduction of HDL in males having mated once; Ruther et al., 2009; Blaul and Ruther, 2012). Markings deposited by multiply mated males are thus less attractive to females than markings deposited by virgin males. The fact that significant sperm depletion occurs already after seven consecutive matings indicates that pheromone quantity may be used by females during mate choice as an honest signal of male fertility (Ruther et al., 2009). Even if having moved away from the territory when mounted on the female's back during courtship and copulation, territorial males usually return to their territory before intensifying marking activities (Mair and Ruther, 2018). Instead of applying new pheromonal spots elsewhere, they thus strengthen the signal of their earlier pheromonal deposits by adding further amounts of the pheromone. Females attracted to stronger pheromonal signals are therefore also attracted to reproductively and territorially successful males.

Further evidence that the amount of pheromone is indeed an honest indicator of male quality comes from studies on the biosynthetic pathway of the major pheromone components RSHDL and RR-HDL (Figure 3). A chemical sexual signal can become honest, if its production is costly for the producer (Zahavi, 1975; Johansson and Jones, 2007). Often pheromone production involves biosynthetic pathways connected to other important metabolic functions effecting, for example, the individual's immunological defense against pathogens (Rantala et al., 2003) or the production of gametes (Thomas and Simmons, 2009). Linoleic acid ((9Z,12Z)-octadeca-9,12-dienoic acid, LA), a polyunsaturated fatty acid (PUFA), is needed for the production of sperm in animals (Wathes et al., 2007). Stable isotope labeling experiments revealed that LA is also a precursor for the biosynthesis of HDL in Nasonia males (Blaul and Ruther, 2011). This indicates a trade-off between abdominal sex pheromone production and the production of sperm. Consistently, males emerging from hosts artificially enriched in LA produce both larger amounts of sperm and larger amounts of HDL (Blaul and Ruther, 2011).

\section{Biosynthesis of the Male Marking Pheromone}

Recent studies on the pheromone biosynthesis revealed that $N v$ has a $\Delta 12$-desaturase enabling them to synthesize LA from oleic acid (OA; Blaul et al., 2014; Semmelmann et al., 2019b; see Figure 3). Wang et al. (2015) found a predicted desaturase gene Nasvi2EG017727 to be 800-fold higher expressed in $N v$ males while a highly similar paralogue was expressed unbiasedly in both males and females. Functional characterization of the two gene products Nvit_D12a and Nvit_D12b subsequently revealed

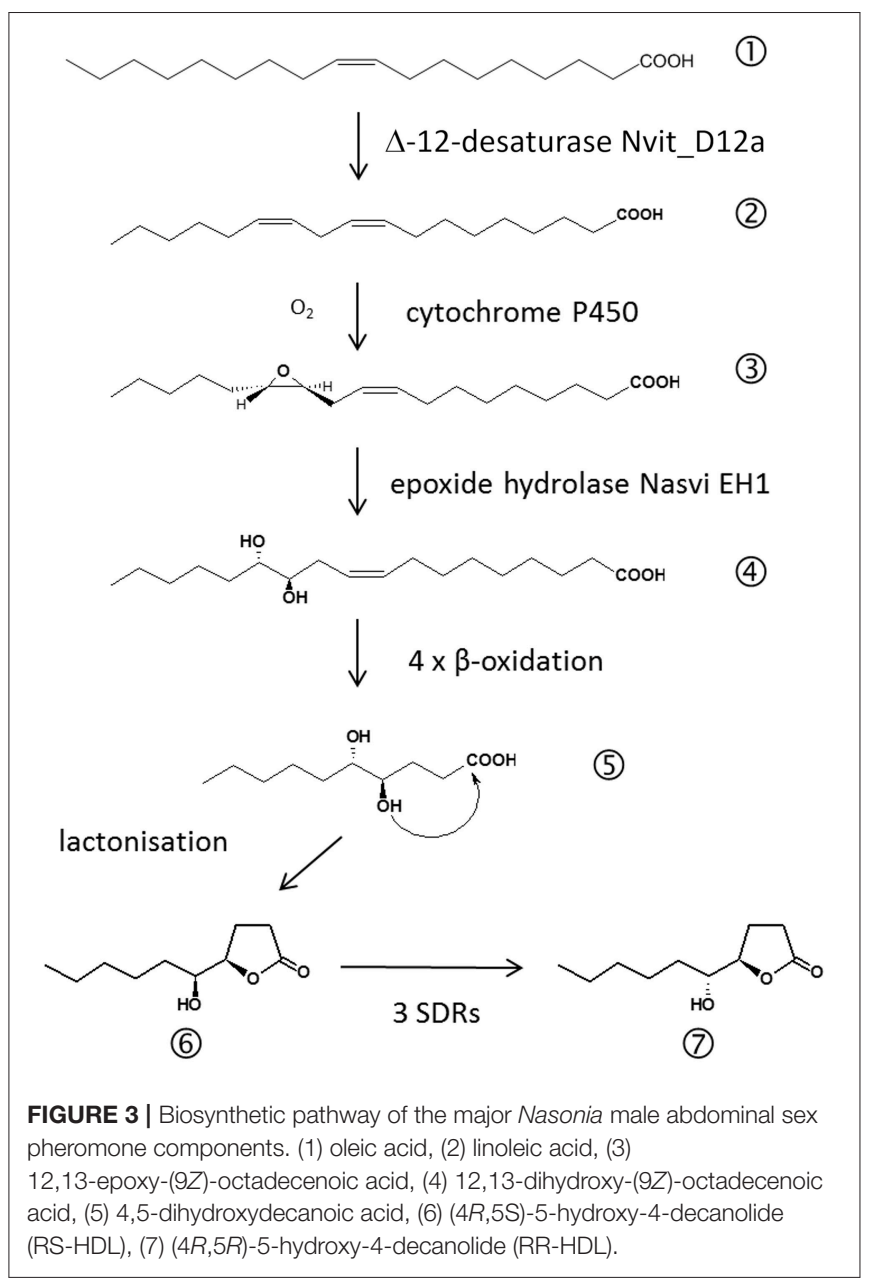

that both have in fact $\Delta 12$-desaturase activity. However, only Nvit_D12a was found to be expressed in the male pheromone gland suggesting that it acquired a specialized function in $N v$ for the production of LA as a pheromone precursor (Semmelmann et al., 2019b). The fact that $N v$ males are capable of synthesizing LA by themselves challenged the postulated importance of LA as a limited resource. However, a recent study (Brandstetter and Ruther, 2016) revealed that males albeit synthesizing LA still benefit from the dietary uptake of LA during larval development. Males reared on LA enriched hosts were able to produce significantly higher amounts of HDL than males reared on hosts enriched in $\mathrm{OA}$ indicating that the conversion of $\mathrm{OA}$ into LA is a costly process (Brandstetter and Ruther, 2016). The next step of the HDL biosynthesis is an epoxidation of LA to 12,13-epoxy-(9Z)-octadecenoic acid. This conversion is typically catalyzed by cytochrome P450 enzymes (CYP450; Oliw, 1994). CYP450 genes are highly abundant in the $N v$ genome (Oakeshott et al., 2010), but the question which of the 92 candidate genes is involved in the pheromone biosynthesis needs further investigation. The next step of the HDL biosynthesis is the hydrolysis of 12,13-epoxy-(9Z)-octadecenoic acid to 12,13-dihydroxy-(9Z)-octadecenoic acid by the epoxide 
hydrolase Nasvi-EH1 (Abdel-Latief et al., 2008). Gene expression experiments using in situ RT-PCR suggested that this step occurs in the rectal papillae, twins of secretory organs adjacent to the rectal vesicle (Davies and King, 1975; Abdel-Latief et al., 2008). Four steps of chain shortening by $\beta$-oxidation and lactonization of the resulting 4,5-dihydroxydecanoic acid then eventually leads to RS-HDL. RR-HDL is produced in $N v$ males by epimerization of RS-HDL using short-chain dehydrogenases/reductases (SDRs) encoded by the three genes NV10127, NV10128, and NV10129 positioned on chromosome 1 (Niehuis et al., 2013; Ruther et al., 2016). The sequences of the Nasonia SDR genes are highly similar to those of enzymes catalyzing the deactivation of prostaglandins which serve various hormonal functions in insects (Stanley, 2006). This suggests that the SDRs epimerizing RS- to RR-HDL in $N v$ have evolved secondarily from these enzymes by gene duplication and neofunctionalization (Niehuis et al., 2013; Ruther et al., 2016). The three homologous SDRs differ significantly in their ability to epimerize RS- to RR-HDL. The investigation of the underlying sequence-activity relationships by site-directed mutagenesis experiments revealed that six amino acids at the C-terminus were crucial for the efficient epimerization of RS- to RR-HDL (Semmelmann et al., 2019a).

\section{Strategies at the Natal Host Patch in the Other Nasonia Species}

The Nasonia species differ profoundly in the behavior they exhibit at the natal host patch: while virtually all females of $N v$ emerge from the host puparium as virgins, almost all females of $\mathrm{Ng}$ mate inside the host prior to emergence (Drapeau and Werren, 1999; Leonard and Boake, 2006; Giesbers et al., 2013; Ruther et al., 2014), and within-host-mating (WHM) rates in $N l$ and $\mathrm{No}$ lay between those of $\mathrm{Nv}$ and $\mathrm{Ng}$ (Leonard and Boake, 2006; Giesbers et al., 2013). Giesbers et al. (2016) suggested that the high WHM rate in $\mathrm{Ng}$ results from the fact that $\mathrm{Ng}$ males refrain from chewing an exit hole into the puparium and thus impede the emergence of virgin females. Consistently, in $\mathrm{Ng}$, females emerge prior to males (Mair and Ruther, 2018). Instead of building up territories, $\mathrm{Ng}$ males readily disperse from the host after emergence and engage less often in aggressive interactions than males of $N v$ (Leonard and Boake, 2006; Mair and Ruther, 2018). Nevertheless, $\mathrm{Ng}$ males produce similar amounts of HDL as males of $N v$ (Ruther et al., 2014) and use the abdominal sex pheromone to mark the substrate in the surroundings of the natal host patch (Mair and Ruther, 2018). Mair and Ruther (2018) suggested that $\mathrm{Ng}$ marking, although useless when all females are already mated, is of adaptive importance in microsympatry with $N v$. When wasps of $N v$ and $N g$ develop within the same host individual, an increased number of $\mathrm{Ng}$ females emerges as virgins because $N v$ males chew an exit hole into the puparium through which virgin $\mathrm{Ng}$ females can escape (Giesbers et al., 2016). In these situations, $\mathrm{Ng}$ males marking the substrate with abdominal sex pheromone may be able to attract and copulate with these unmated females (Mair and Ruther, 2018). Future observations of wasps emerging naturally from hosts multiparasitized by both $N v$ and $\mathrm{Ng}$ could give valuable insights into the dynamics occurring between these two species at the natal host patch in microsympatry.

A further difference between the Nasonia species concerns the composition of the marking pheromone. The male abdominal sex pheromone of $\mathrm{Nl}, \mathrm{No}$, and $\mathrm{Ng}$ as well as the one of the closely related species Trichomalopsis sarcophagae consists of RS-HDL and $M Q$, lacking significant amounts of the third component RRHDL (Niehuis et al., 2013). This suggests that RS-HDL/MQ is the ancestral pheromone composition and RR-HDL has evolved in $N v$ as an adaptation to avoid interspecific mating caused by signal interference in areas of sympatry. Consistent with this hypothesis, RR-HDL has no effect on the pheromone response of $\mathrm{Ng}$ females while it synergizes the response to RS-HDL in $N v$ females (Niehuis et al., 2013). Strikingly, genes encoding the SDRs that catalyze the epimerization of RS- to RR-HDL are also present in the genome of $\mathrm{Ng}$ and in vitro assays showed that the enzymes are also capable of catalyzing the epimerization albeit with a decreased efficiency. However, proteomic analyses of the pheromone glands showed a much higher expression in $N v$ suggesting that differential SDR gene expression underlies the pheromone difference between $N v$ and the other Nasonia species (Ruther et al., 2016). Why $N v$ is the only Nasonia species that evolved an additional pheromone component remains unclear so far, but likely involves the differences in the mating behavior, in particular the complete lack of WHM and thus strong dependency on the correct identification of conspecific male sex pheromone markings to find mates in this species.

The behavior of males of No at the natal host patch is largely unknown. Males of No produce less $\mathrm{HDL}$ than males of $\mathrm{Ng}$ and three quantitative trait loci (QTL; on chromosomes 1,4 , and 5, respectively) have been identified that are significantly correlated with male pheromone quantity in these two species (Diao et al., 2016). However, the functional characterization of genes at these loci as well as the ecological implications of this difference in pheromone quantity necessitates further investigation. It would be interesting to study whether HDL production and the release of the abdominal sex pheromone are further correlated to different behavioral strategies at the natal host patch, e.g., rendering pheromone deposition by No males less important than in the other Nasonia species.

$\mathrm{Nl}$ is characterized by relatively low WHM rates of about 10\% (Drapeau and Werren, 1999; Leonard and Boake, 2006; Giesbers et al., 2013) and engage in aggressive interactions on the host after emergence (Leonard and Boake, 2006) indicating that $\mathrm{Nl}$ males may exhibit territorial behavior similar to that of $N v$ males. The amount of HDL produced by males of $N l$, however, has not been investigated so far. A detailed comparative study of male and female behavior of all Nasonia species at the natal host patch coupled with behavioral bioassays using multiparasitized hosts may prove valuable for the understanding of how differences in the pheromone communication at the natal host patch have evolved and how the different Nasonia species are able to coexist in areas of microsympatry. In addition, little is known about the behavioral variability within Nasonia species and how this variability influences interspecific dynamics in the field. 


\section{Male Mate Recognition-Female Derived Contact Sex Pheromones}

When encountering another individual, males have to decide whether or not the individual is a possible mating partner to appropriately adjust subsequent decisions [Figure 2(2)]. In $N v$, females are typically followed and courted by the males, whereas male competitors are either attacked or dominated and chased off (van den Assem et al., 1980a). In addition, as a measure of prezygotic reproductive isolation, males should avoid courting heterospecific females or at least prefer conspecific over heterospecific ones if costs imposed by courting and copulating with the wrong mating partner are considerably high. In insects, male courtship is often induced by chemical stimuli distributed over the females' cuticle (Lockey, 1988; Howard and Blomquist, 2005; Blomquist and Bagnères, 2010; Wyatt, 2014). These chemicals can be washed off using nonpolar solvents such as hexane or pentane, which indicates that the chemicals eliciting courtship behavior are cuticular lipids [CLs; Table 1(2)]. One major class of CLs are the cuticular hydrocarbons (CHCs) which primarily function as a protection shield against desiccation (Lockey, 1988; Gibbs, 1998) and play important roles in recognition processes in a wide variety of insect taxa (Singer, 1998; Blomquist and Bagnères, 2010). CHCs are the most abundant CLs found on the insects' cuticular surface and are easily detectable and identifiable by gas chromatography and mass spectrometry (GC/MS). Other CLs are the more polar lipids such as aldehydes, alcohols, ketones, wax esters, or non-volatile fatty acid derivatives (NFADs) some of which are not detected by standard GC/MS methods without prior derivatization (Buckner, 1993; Kühbandner and Ruther, 2015). As a result, they are often neglected in studies investigating mate recognition in insects and the term CHCs is often erroneously used interchangeably with CLs. To unambiguously show the behavioral effect of CHCs in recognition processes it is, however, necessary to separate the CHCs from the more polar CLs prior to their use in behavioral bioassays. This can be achieved easily by fractionating complete CL extracts on silica gel columns. In addition, recent studies have shown that more polar lipids (Yasui et al., 2003; Eliyahu et al., 2008; Kühbandner et al., 2012; Salerno et al., 2012; Stökl et al., 2014; Keppner et al., 2017) and even peptides (Turillazzi et al., 2006) can elicit behavioral responses in insects and are likely used as contact sex pheromones far more often than previously thought.

\section{Male Mate Recognition in $\mathbf{N}$. vitripennis}

In $N v$, males recognize females based on the females' CHCs alone and do not rely on additional, more polar compounds (Steiner et al., 2006). The CHC profile in Nasonia detectable by classical GC/MS techniques consists of hydrocarbons ranging from C25 to C37 including n-alkanes, mono-, di-, tri-, and tetramethylalkanes as well as few alkenes (Carlson et al., 1999; Steiner et al., 2006; Niehuis et al., 2010; Buellesbach et al., 2013, 2018; Mair et al., 2017). Both quantitative and qualitative differences in the composition of CHCs exist between females and males of $N v$ (Carlson et al., 1999; Steiner et al., 2006; Buellesbach et al., 2013, 2018). Compared to males, $N v$ females possess higher relative amounts of hydrocarbons with chain lengths shorter than $\mathrm{C} 30$ as well as higher relative amounts of methyl-branched alkanes with central branching positions (e.g., 9-, 11-, 13-, 15-methylalkanes or 9,x-, 11,x-, 13,x-, 15,xdimethylalkanes) whereas males possess higher relative amounts of methyl-branched alkanes with marginal branching positions (e.g., 3-, 5-, 7-methylalkanes or 3,x-, 5,x-, 7,x-dimethylalkanes) as well as higher relative amounts of alkenes (Steiner et al., 2006; Buellesbach et al., 2013, 2018). Males of $N v$ use the sexspecific differences in the $\mathrm{CHCs}$ to distinguish females from males by means of antennal contact during encounters (Steiner et al., 2006). In bioassays, female CHCs applied to dummies (solvent-washed male corpses) elicited arrestment and courtship behavior including copulation attempts, whereas male CHCs did not (Steiner et al., 2006; Mair et al., 2017).

In addition to sex-specific differences, the composition of CLs differs among all four Nasonia species (Carlson et al., 1999; Steiner et al., 2006; Raychoudhury et al., 2010a; Buellesbach et al., 2013; Mair et al., 2017). More specifically, compared to females of $\mathrm{Ng}$, females of $\mathrm{N} v$ possess higher relative amounts of n-alkanes and monomethylalkanes, whereas females of $\mathrm{Ng}$ possess higher relative amounts of di-, tri-, and tetramethylalkanes (Mair et al., 2017). In addition, Niehuis et al. (2010) showed that males of $N v$ possess larger relative amounts of the three alkenes 9-C31ene, 9C33ene, and 7-C33ene than males of $\mathrm{Ng}$. However, in bioassays with fractionated female extracts (containing only CHCs), $\mathrm{Nv}$ males showed courtship and copulation attempts equally often toward both dummies applied with CHCs of $N v$ females and those applied with CHCs of $\mathrm{Ng}$ females (Mair et al., 2017). Furthermore, in bioassays with living couples, $N v$ males seem to even court females of $T$. sarcophagae, a species closely related to the genus Nasonia which possesses a relatively similar $\mathrm{CHC}$ composition compared to $N v$ (Niehuis et al., 2013; Buellesbach et al., 2018). Overall, $N v$ males are hardly selective in the choice of their mating partners (Giesbers et al., 2013; Buellesbach et al., 2014,2018 ) indicating that mating with the wrong partner does not impose considerable fitness costs on them. Although repeated courtship and mating reduce male longevity (Burton-Chellew et al., 2007b), this has probably only little effect on overall male fitness in nature considering that males with continuous contact to females lived for more than 9 days in bioassays, a time span in which most or all females have typically emerged from the host puparium and mated already (Mair and Ruther, 2018). In addition, males can mate multiple times before suffering from sperm depletion (seven or more matings; Whiting, 1967; Ruther et al., 2009; Chirault et al., 2016). Apart from losing time and energy spent in misdirected courtship, single mistakes in mate choice are thus not severely costly for $N v$ males.

\section{Male Mate Recognition in the Other Nasonia Species}

Similar to $N v$, males of the other three Nasonia species also engage in courtship and copulation with heterospecific females (Giesbers et al., 2013; Buellesbach et al., 2014; Mair et al., 2017). Solely in $\mathrm{Ng}$ it has been shown that males show significant discrimination against heterospecific mating partners in living couples: They refrain from starting courtship more often when confronted with females of No than with conspecific females (Buellesbach et al., 2014) and start courtship faster when 
confronted with conspecific as compared to $N v$ females (Mair et al., 2017). This preference for conspecific females was absent, however, in bioassays with dead females and when males were confronted with female extracts (CLs) or fractionated female extracts (CHCs) applied to dummies (Giesbers et al., 2013; Mair et al., 2017). This indicates that $\mathrm{Ng}$ males use additional species-specific characteristics such as visual cues, tactile cues or differences in the females' behavior to differentiate between con- and heterospecific mating partners. Furthermore, the class of substances used by males in the recognition of females differs between $N v$ and $N g$. While males of $N v$ rely solely on the females' CHCs (Steiner et al., 2006; Mair et al., 2017), conspecific courtship in $\mathrm{Ng}$ males is only induced when confronted with complete CL extracts of conspecific females including the more polar lipids (Mair et al., 2017). Surprisingly, although conspecific female CHCs are not sufficient to induce courtship in $\mathrm{Ng}$ males, heterospecific female CHCs are (Mair et al., 2017). A shift to other chemical messengers used in mate recognition must therefore have happened in $\mathrm{Ng}$ (Mair et al., 2017). However, the cause leading to this shift and the reasons why heterospecific female $\mathrm{CHCs}$ remain attractive to $\mathrm{Ng}$ males are still unclear.

In $\mathrm{No}$, bioassays with complete CL extracts indicate that males of No might be able to discriminate against heterospecific females belonging to any other Nasonia species (Buellesbach et al., 2013; Giesbers et al., 2013). In mating trials with living couples, however, males of No courted con- and heterospecific females equally often (Buellesbach et al., 2014). Nevertheless, a more detailed comparative study of the different males' discriminative abilities which, instead of merely looking at presence/absence of courtship, includes more subtle behavioral parameters such as temporal behavioral patterns is widely lacking to date. In addition, the chemical basis of mate recognition in $\mathrm{No}$, and $\mathrm{Nl}$ has not been solved in detail yet and the potential effects that male discriminatory behavior has in more natural environments under microsympatry still needs to be elucidated. Based on the evidence gained so far, it is, however, unlikely that males of Nasonia contribute much to interspecific prezygotic reproductive isolation among the Nasonia species.

A recent study using direct laser desorption/ionization mass spectrometry revealed the additional presence of some very long chain alkanes and alkenes on the cuticles of $\mathrm{Nv}, \mathrm{Ng}$, and $\mathrm{Nl}$ which were not detected in previous studies (Bien et al., 2019). Whether these chemicals play a role in the species-specific mate recognition, however, needs further investigation.

\section{Courtship and Female Mate Discrimination-The Male Oral Sex Pheromone}

In contrast to males, females of all Nasonia species discriminate against heterospecific males [Raychoudhury et al., 2010a; Giesbers et al., 2013; Buellesbach et al., 2014; Ruther et al., 2014; Mair et al., 2017, 2018; Figure 2(3)]. The means by which they achieve discrimination, however, remain unknown to date and the identification of chemical stimuli involved failed so far. One means by which a female gets the possibility to choose between different mating partners is the male's courtship display. During courtship, the male mounts the female and starts moving its head along the female's antennae, a behavior termed head-nodding. Head-nodding comes in repetitive series consisting of speciesspecific patterns of long and short intervals between nodding movements, and is accompanied by stroking movements of the male's antennae and legs over the female's head and eyes (Barrass, 1960, 1961; van den Assem et al., 1980b; van den Assem and Werren, 1994; Jachmann and van den Assem, 1996; van den Assem and Beukeboom, 2004). Head-nodding cycles typically consist of one slow upward stroke followed by several faster nods, a temporal pattern which is likewise exhibited in all Nasonia species but differs in details such as the number of fast nods and the length and number of head-nodding cycles (van den Assem and Vernel, 1979; van den Assem et al., 1980b, 1981; van den Assem and Werren, 1994). Along with these courtship movements, an oral male sex pheromone is transferred from the male's mouthparts to the female's antennae [van den Assem et al., 1980b, 1981; Ruther et al., 2010; Ruther and Hammerl, 2014; Table 1(3)] potentially giving the female another means to discriminate between different mating partners. When accepting the courting male, the female shows receptivity by flattening the antennae, lowering the head and opening the genital orifice, and copulation follows (van den Assem and Vernel, 1979; van den Assem et al., 1980b; van den Assem, 1986). After copulation, the male usually returns to the courtship position and performs several more head-nodding movements before unmounting (van den Assem and Visser, 1976). It is likely that during this post-copulatory courtship the male transfers an additional amount of the oral sex pheromone. As a result of courtship, receptivity and copulation, a switch happens in the females' behavior: mated females are no longer attracted to the male abdominal sex pheromone (pheromone switch; van den Assem, 1986; Ruther et al., 2007, 2014; Steiner and Ruther, 2009a; Ruther and Hammerl, 2014; Lenschow et al., 2018), typically refrain from mating again (receptivity switch; Holmes, 1974; van den Assem and Visser, 1976; Grillenberger et al., 2008) and become restless instead and switch to dispersal and host-seeking behavior (King, 1993; King et al., 2000; Steiner and Ruther, 2009b; Ruther et al., 2014).

\section{Receptivity Necessitates the Transfer of the Oral Male Sex Pheromone}

The transfer of the oral male sex pheromone during courtship is a prerequisite for the induction of receptivity in females. During head-nodding the male extrudes its mouthparts and transfers the aphrodisiac to the female's antennae (van den Assem et al., 1980b, 1981; Ruther et al., 2010; Ruther and Hammerl, 2014). Males possess a voluminous mandibular gland which has been suggested to be the source of the aphrodisiac (Miko and Deans, 2014). By experimentally covering the mouthparts with a drop of glue, the transfer of the pheromone can be inhibited resulting in the prevention of female receptivity signaling (van den Assem et al., 1980b; Ruther et al., 2010). The substances that are responsible for inducing receptivity are, however, unknown to date (Ruther and Hammerl, 2014) and the establishment of experimental procedures allowing to test pheromonal extracts, fractions of these extracts and synthetic pheromone components has turned out to be rather difficult (personal observation, both authors). van den Assem et al. (1980b) suggested the pheromone 
to be volatile. They puffed the headspace of courting couples into a chamber containing a constrained couple with a sealed male and reported that the female became receptive. Our frequent attempts to repeat this experiment, however, were unsuccessful so far. We therefore suggest that the ominous aphrodisiac of $N v$ males is non-volatile. Females of $N v, N g$, and $N l$ typically show receptivity during the first upwards stroke in a head-nodding series (van den Assem and Werren, 1994). It is thus likely that the pheromone has to be applied in due time with this movement.

\section{The Pheromone Switch}

After mating, $N v$ females are no longer attracted to the male abdominal sex pheromone. This pheromone switch occurs fast (within minutes) and is long-lasting (at least 6 days; van den Assem, 1986; Ruther et al., 2007, 2014; Steiner and Ruther, 2009b; Ruther and Hammerl, 2014). As during copulation a single male usually transfers sufficient sperm to fertilize all eggs the female is likely able to lay (Holmes, 1974; Chirault et al., 2016), not being attracted to male territorial markings is reasonable for mated females and gives them the opportunity to switch to host-seeking behavior instead (Ruther et al., 2007; Grillenberger et al., 2008). In addition, Lenschow et al. (2018) argue that the pheromone switch has evolved as a result of a male strategy to prevent females from encountering and copulating with other males. Responsible for the pheromone switch is the application of the male oral sex pheromone to the females' antennae during courtship (Ruther et al., 2010). Courtship movements, copulation, the transfer of sperm or ejaculate and post-copulatory courtship, on the other hand, are not necessary (Ruther et al., 2010; Ruther and Hammerl, 2014). In bioassays, the pheromone switch can even be triggered by merely bringing the antennae of virgin females into contact with male-derived head extracts (Ruther and Hammerl, 2014). More precisely, the active components of the oral sex pheromone that elicit the pheromone switch have been identified as the three fatty acid esters ethyl oleate, ethyl linoleate and ethyl $\alpha$-linolenate (Ruther and Hammerl, 2014). The mere antennal contact with these three substances thus resulted in a change in the females' response to the abdominal sex pheromone. A study on the neuromodulatory mechanisms underlying this behavioral plasticity showed that it involves the release of dopamine (DA; Lenschow et al., 2018). In bioassays, feeding the DA receptor antagonist chlorpromazine prevented the pheromone switch while the injection of DA into virgin females rendered them unresponsive to the abdominal sex pheromone. As dopamine is also involved in appetitive olfactory learning (Waddell, 2013; Lenschow et al., 2018), this suggests that DA plays a key role in mediating olfactory plasticity in $N v$. The pheromone switch in $N v$ females is not only induced by conspecific males but can be similarly induced by heterospecific males and a similar switch has been demonstrated in females of $\mathrm{Ng}$ (Ruther et al., 2014). It is thus likely that the pheromone switch and the substances eliciting the switch are not species-specific but instead represent an ancestral state in the Nasonia genus.

\section{The Receptivity Switch}

The receptivity switch is a second switch that happens in females after mating and concerns the females' willingness to re-mate. Females of $N v$ typically mate only once during their lifetime
(Holmes, 1974; van den Assem and Visser, 1976; Grillenberger et al., 2008). When being courted by a second male after having already mated previously, females usually refuse to become receptive and re-mating does not occur (Holmes, 1974; van den Assem and Visser, 1976). In contrast to the pheromone switch, however, this receptivity switch is connected to the postcopulatory courtship exhibited by males after copulation (van den Assem and Visser, 1976; Boulton and Shuker, 2015). The actual copulatory act and the transfer of seminal fluids, on the other hand, are not important (van den Assem and Visser, 1976). van den Assem and Visser (1976) observed in behavioral bioassays that females showed a second receptivity signal during post-copulatory courtship. They thus hypothesized that females need to show receptivity twice before the receptivity switch happens. As courtship involves the transfer of a pheromone, it is likely that this is also true for post-copulatory courtship. The male oral sex pheromone consists of various compounds that are not involved in the pheromone switch (Ruther and Hammerl, 2014). It is thus likely that some of these compounds are involved in the receptivity switch, a hypothesis which still necessitates further investigation. Reported re-mating rates differ among Nasonia species and between different Nasonia strains (Leonard and Boake, 2008; Geuverink et al., 2009). In addition, re-mating appears to increase in strains having been reared in the laboratory over prolonged time (van den Assem and Jachmann, 1999; Burton-Chellew et al., 2007a). Studies investigating the receptivity switch therefore need to take into account the individual history of the investigated strains and should ideally work with field-collected outbred strains.

\section{Olfactory Host Finding-The Role of Host Habitat Odors and Host Kairomones Olfactory Host Finding in $N$. vitripennis}

After mating, females of $N v$ become restless and start searching for new hosts [King, 1993; King et al., 2000; Ruther et al., 2014; Figure 2(4)]. Because hosts are usually distributed patchily in the environment occurring in birds' nests and on rotting carcasses, finding adequate hosts is a challenging task for females. Using four polymorphic microsatellites, Grillenberger et al. (2008) found a clear isolation between populations of $N v$ at two sampling sites in the Netherlands and Germany located about $300 \mathrm{~km}$ apart. Nevertheless, $N v$ females are able to disperse over long distances as indicated by the lack of genetic population substructure over a range of $100 \mathrm{~km}$ in a field study in the US using eight microsatellite markers (Grillenberger et al., 2009a). During long-distance dispersal, females are supposedly drifting as aerial plankton by the use of wind currents to reach new habitats (Grillenberger et al., 2009a). For orientation over intermediate and short distances, on the other hand, active chemotaxis toward host habitat odors has been suggested (Whiting, 1967). Consistently, material taken from birds' nests and carcasses attracts mated $N v$ females [Peters, 2011; Frederickx et al., 2013; Table 1(4)]. One compound which has been shown to be particularly attractive to mated females is dimethyldisulphide (DMDS), a major component found in the headspace of decaying meat (Kasper et al., 2012). Mated females tested in olfactometer experiments showed a clear affinity toward DMDS whereas all 
other tested compounds of rotten meat extracts did not elicit preferential behavior (Frederickx et al., 2013). Adult $N v$ arrive at carcasses at an early stage of decomposition when adult host flies and larvae are already present, but host pupae have not developed yet (Voss et al., 2009). After arriving at a suitable host habitat, females most likely rely on short-range or contact kairomones originating from host fly puparia to find and identify adequate hosts on a carcass or inside birds' nests, respectively. In bioassays using a still-air olfactometer, females preferred right after mating the odor of hosts over that of conspecific males (Steiner and Ruther, 2009b).

\section{Olfactory Host Finding in the Other Nasonia Species}

Female dispersal and the chemical basis of host location in the other Nasonia species have not been investigated to date. Due to their similar life history, morphology and general chemosensory abilities, it is, however, likely that all Nasonia females use similar modes of transport and chemotaxis. Whether they respond to the same chemical compounds during their search for new host patches, however, needs further investigation. As $\mathrm{Ng}$ is specialized on pupae of Protocalliphora, it is likely that females of $\mathrm{Ng}$ (and likely also females of $\mathrm{No}$ ) are not attracted to odors originating from carcasses but rely solely on cues associated with birds' nests.

\section{Oviposition and Sex Ratio Adjustment-Chemical Assessment of Host Quality}

When females encounter a host puparium after arrival at a new host patch, they need to decide firstly whether to lay eggs, secondly how many eggs to lay and thirdly how many eggs shall develop into females or males, respectively [Figure 2(5)]. Nasonia wasps, like all hymenopterans, are haplodiploid, i.e., females are diploid and emerge from fertilized eggs, whereas males are haploid and develop from unfertilized eggs (Heimpel and de Boer, 2008). During oviposition, mated females are capable of actively adjusting the sex ratio of their offspring in response to varying environmental factors essential for offspring survival and performance such as the number, quality, and parasitization status of the hosts (Verhulst et al., 2010).

\section{Host Quality and Offspring Fitness}

A high nutritional value of host pupae positively influences offspring condition which is reflected in a shorter development time and increased body size of both female and male adults (Rivers and Denlinger, 1995a; Hoedjes et al., 2014). Females emerging from hosts of lower quality are smaller and produce fewer eggs. Similar to most parasitoids, females of Nasonia are supposed to be unable to biosynthesize fatty acids de novo (Visser et al., 2010). Despite compensation for this inability through host feeding in the course of oviposition, lipids acquired prior to emergence are thus essential and limiting for adult females (Rivero and West, 2002, 2005; Sykes et al., 2008). In addition, males having developed in hosts rich in linoleic acid produce higher amounts of HDL and sperm, and are thus most likely able to attract and inseminate more females (Blaul and Ruther, 2011). The amount of host nutrients available per individual, however, decreases with increasing parasitoid clutch size or when a host is parasitized by more than one female. In addition, due to local mate competition (LMC) between male offspring at the natal host patch after emergence, females typically produce increased numbers of males under superparasitism to increase the mating success of their male offspring in the competition for mates (Werren, 1980, 1983; Shuker et al., 2006; Burton-Chellew et al., 2008). Therefore, it is crucial for the females' fitness to optimize clutch size based on the amount of nutrients available (i.e., host quality) and offspring sex ratio based on the status of pre-parasitization of the encountered host.

\section{Host Quality Assessment}

When encountering a host, the female inspects the fly puparium from outside with her antennae and the tip of her abdomen before drilling into it with her ovipositor (Edwards, 1954; King and Rafai, 1970). The tip of the ovipositor possesses pores containing chemoreceptors which are likely used to chemically inspect the status of the host [Edwards, 1954; King and Rafai, 1970; Table 1(5)]. If the host is deemed suitable for oviposition, venom is injected into the fly pupa, and eggs are laid onto the pupa inside the puparium (Wylie, 1965; Ratcliffe and King, 1967). During the process of drilling, $N v$ females are able to assess the nutritional quality as well as the pre-parasitization status of the host pupa (Wylie, 1965; King and Rafai, 1970; Blaul and Ruther, 2011).

$N v$ females discriminate between pupae of different fly species and prefer pupae of Sarcophaga spp. over those of Musca domestica (Rivers and Denlinger, 1995a). In addition, they discriminate between different host sizes and hosts with different nutritional values (Rivers and Denlinger, 1995a; Blaul and Ruther, 2011). On dead or small hosts, fewer eggs are laid, and offspring sex ratios are shifted in favor of males (Rivers and Denlinger, 1995a). In addition, females prefer LA-enriched hosts over those poor in LA (Blaul and Ruther, 2011). Given the essential function of LA in the production of sperm and HDL, this is highly adaptive. Additional cues used for the assessment of host quality are, however, to be discovered and offer promising opportunities for further research.

\section{Assessment of Pre-parasitization}

In addition to general host quality, $N v$ females are able to discriminate between parasitized and non-parasitized hosts (Wylie, 1965; King and Rafai, 1970; Holmes, 1972; Werren, 1980; King and Skinner, 1991; Shuker and West, 2004) and are even able to distinguish hosts pre-parasitized by conspecific females from those previously parasitized by heterospecific ones (Ivens et al., 2009). In general, pre-parasitized hosts are rejected more often (Ivens et al., 2009). If females decide to oviposit nonetheless, fewer offspring and higher relative numbers of males are produced (Wylie, 1965; Holmes, 1972). The means by which ovipositing females assess the parasitization status of hosts has not been identified yet, but chemical messengers are likely involved (Wylie, 1965; King and Rafai, 1970; Holmes, 1972). Holmes (1972) hypothesized that female venom injected into the fly pupa during oviposition might act as a cue and King and Rafai (1970) recognized changes 
in the hosts' haemolymph composition after the injection of female venom.

Cues potentially used by females to assess the hosts' preparasitization status are the venom itself and venom-induced changes in the host pupae. The venom of $N v$ is acidic and consists of different amines, peptides and non-glycosylated proteins (Rivers et al., 2006). In total, 79 proteins and peptides have been identified that belong to different functional classes (de Graaf et al., 2010; Martinson et al., 2017; effects of individual compounds are discussed in detail in Danneels et al., 2010). The most obvious effect of $N v$ venom on host pupae is the developmental arrestment followed by the death of the pupae after some time depending on both the fly species and pupal age (Rivers and Denlinger, 1994a). After envenomation, a blackening of the injection site can be observed, a result of melanization of the damaged tissue initiated by the host as a defense mechanism (Rivers et al., 1993; Siebert et al., 2015). A cascade of metabolic changes is subsequently initialized in the host (Rivers and Denlinger, 1994b, 1995b; Rivers and Yoder, 1996; Rivers et al., 2002a,b; Martinson et al., 2014, 2016, 2019; Mrinalini et al., 2015) leading, among other effects, to the mobilization of nutrients for the developing wasp larvae and increased fatty acid biosynthesis (Rivers et al., 1993, 2002a; Rivers and Denlinger, 1995b; Mrinalini et al., 2015). The tremendous changes in the composition and relative amount of different substances found in hosts after envenomation have notable potential of being used in host assessment by female wasps. Which substances are of relevance during host assessment and whether the used substances are constituents of the venom or rather emerge by means of physiological changes induced by venom injection remains, however, to be elucidated. Further investigations of the chemoreceptors found on the ovipositor as well as controlled bioassays might be promising.

\section{Host Discrimination in the Other Nasonia Species}

Females of $\mathrm{Ng}$ are also able to discriminate between different host species and prefer pupae of Protocalliphora sialia over those of Sarcophaga bullata (Desjardins et al., 2010) which is in accordance with the occurrence of $\mathrm{Ng}$ in birds' nests rather than on carcasses. Bioassays on host discrimination in $\mathrm{Nl}$ and No have not been conducted so far, but it is likely that they are similarly able to distinguish different host species and host qualities. Also, taking a deeper look into the venom composition of the other three Nasonia species might give insights into mechanisms used by females to further differentiate between conand heterospecifically pre-parasitized hosts.

\section{ASSOCIATIVE OLFACTORY LEARNING}

\section{Associative Olfactory Learning in N. vitripennis}

The olfactory localization of hosts by Nasonia females is not completely inherent but employs a dynamic learning and conditioning scheme that depends on the memory of hostassociated chemical cues. Females of $N v$ are able to memorize odors they perceive during host assessment and oviposition and use these cues during the subsequent search for new hosts. The inspection of a single host puparium for $1 \mathrm{~h}$ in the presence of the synthetic volatile furfuryl heptanoate (FFH; the conditioned stimulus) for example led to the preference of FFH in subsequent olfactometer bioassays (Schurmann et al., 2009). This conditioning, however, was non-permanent and the preference vanished after 4 days. Nevertheless, Schurmann et al. (2012) were able to increase memory effects to 6 days by elongating the duration of inspection, repeating conditioning procedures, and allowing the females to perform host-feeding or oviposition in the presence of the conditioned stimulus (cinnamon odor). The physiological mechanisms leading to the formation of a long-term memory are dependent on protein synthesis which is indicated by decreased memory retention to a maximum of 3 days after the injection of the transcription inhibitor actinomycin D after training (Schurmann et al., 2012).

The neuromodulatory mechanisms underlying associative learning in insects involve a variety of different chemical messengers which interact at different levels of the olfactory system (Menzel and Muller, 1996). Two neuromodulators found to be of specific importance in learning are the two biogenic amines dopamine (DA) and octopamine (OA; Unoki et al., 2005, 2006). While DA has usually been associated in insects with aversive learning (i.e., learning to avoid a stimulus when it is associated with a negative experience or punishment), OA has predominantly been associated with appetitive learning (i.e., learning to prefer a stimulus when it is associated with a positive experience or reward Schwaerzel et al., 2003; Unoki et al., 2005). However, although OA seems to be sufficient in inducing appetitive learning in some insects (e.g., honeybees and crickets; Hammer and Menzel, 1998; Matsumoto et al., 2015), it has been shown lately that appetitive learning involves both DA and OA in Drosophila melanogaster (Burke et al., 2012). Similar to D. melanogaster, a recent study indicates that both $\mathrm{DA}$ and $\mathrm{OA}$ are also important for appetitive learning in $N v$ (Lenschow et al., 2018). In behavioral bioassays using oviposition as a reward, mated females of $N v$ have been readily conditioned to being attracted again to the male abdominal sex pheromone, thus reversing the pheromone switch. However, after having been fed DA or OA receptor antagonists prior to conditioning, appetitive learning was prevented. In addition, the oviposition reward could be mimicked completely by the injection of DA and partially by the injection of OA into the abdomen of mated females prior to exposure to the male sex pheromone. This indicates that, similar to D. melanogaster, DA and OA act in a concerted manner on different levels in the olfactory system during appetitive learning in $N v$ (Burke et al., 2012; Lenschow et al., 2018).

\section{Differences in Olfactory Learning Among the Nasonia Species}

Memory retention after associative olfactory conditioning differs among Nasonia species (Hoedjes et al., 2012; Hoedjes and Smid, 2014). In experiments involving only one single conditioning event, memory lasted up to 5 days in $N v$ and $N l$, whereas in $\mathrm{Ng}$ the effect already vanished after 2 days (Hoedjes et al., 2012). In addition, in contrast to females of $N v$, females of $\mathrm{Ng}$ depended on a second conditioning treatment to form 
long-term memory (Hoedjes and Smid, 2014). One possible reason why these differences in memory retention have evolved is the difference in host preference among the Nasonia species (Hoedjes et al., 2011, 2012). $N v$ and $N l$ are generalists which accept pupae of a wide variety of different fly species as hosts (Darling and Werren, 1990; Desjardins et al., 2010). Different fly species prefer different habitats such as birds' nests (e.g., bird blowflies, Protocalliphora spp.; Bennett and Whitworth, 1992) or carcasses (e.g., several species of Sarcophagidae (flesh flies) and Calliphoridae (blow flies); Denno and Cothran, 1976) for oviposition, and the availability of fly pupae in different habitats in the field likely changes over time (Villet et al., 2017). A dynamic learning scheme which allows females to focus during the search for hosts on odors connected to recent successful oviposition experiences might thus be particularly adaptive in these two species (Schurmann et al., 2009, 2012; Hoedjes et al., 2011, 2012). In contrast, $\mathrm{Ng}$ is primarily specialized on pupae of Protocalliphora spp. which are obligate parasites of birds (Darling and Werren, 1990). Considering the consistency of relying solely on birds' nest odors, depending on stronger innate preferences during host-seeking might therefore be advantageous for them (Hoedjes et al., 2011, 2012).

\section{OLFACTORY PERCEPTION-ANTENNAL MORPHOLOGY, ODORANT-BINDING PROTEINS AND CHEMOSENSORY RECEPTORS}

The body parts most obviously used in chemoreception in Nasonia are the wasps' antennae, but chemosensory sensillae have also been found on the wasps' tarsal claws, maxillary palps, labial palps, and on the female's ovipositor (Slifer, 1969). Three types of chemosensory sensillae have been identified in $N v$ (Slifer, 1969; Wibel et al., 1984): thick-walled sensillae are bristle-shaped hollow chitinous structures which contain a single pore on the sensillar tip where the dendrites are exposed. Thick-walled sensillae are mainly located on the antennal tip (11th and 12th antennal segments) as well as on tarsal claws, maxillary and labial palps. In contrast, thin-walled sensillae and multiporous plate sensillae are perforated by many small pores. While thin-walled sensillae are bristle-shaped, plate organs are prominent elongated structures connected tightly to the cuticular surface. Both thinwalled sensillae and multiporous plate sensillae are located on segments three to eleven, sparing the antennal tip (Slifer, 1969). The abundance of the different types of sensillae is sex-specific, with females carrying more multiporous plate sensillae, and thick-walled sensillae than males (Slifer, 1969; Wibel et al., 1984).

Insect sensillae are filled with sensillar lymph, an aqueous liquid which contains various proteins such as odorantbinding proteins (OBPs) and chemosensory proteins (CSPs), i.e., small water-soluble proteins which help to transport the often hydrophobic odor molecules through the aqueous liquid (Vieira and Rozas, 2011; Vieira et al., 2012; Pelosi et al., 2014). During olfaction, odor molecules enter the sensillum through the sensillar pores, bind to OBPs or CSPs and diffuse to chemosensory receptors which are located in the dendritic membrane of chemosensory neurons reaching into the sensillar lymph (Vieira and Rozas, 2011). The chemosensory receptors interact with the odor molecules, and the presence of this interaction is subsequently communicated via electrical signals to the brain where the information is processed (antennal lobe, mushroom bodies, lateral horn). Chemosensory receptors are commonly classified into two main groups: odorant receptors (ORs) associated with the perception of food odors and pheromones and gustatory receptors (GRs) which include, among others, highly conserved carbon dioxide receptors (Jones et al., 2007; Kaupp, 2010).

The number of gene loci coding for OBPs, CPSs and chemosensory receptors are often discussed as indicators of the complexity of olfactory behavior in animals (Robertson and Wanner, 2006; Robertson et al., 2010). In the genome of $N v, 90$ predicted OBPs and 10 predicted CSPs have been identified, and 59 of these OBPs have full expressed sequence tags (EST) support indicating that at least two thirds of the OBP sequences are also expressed (Werren et al., 2010; Vieira et al., 2012; Pelosi et al., 2014). All 90 OBPs of $N v$ have orthologs in $N l$ and $N g$ (Vieira et al., 2012). Compared to the 21 OBPs and 6 CSPs in the honey bee Apis mellifera and the 52 OBPs and 4 CSPs in Drosophila melanogaster (Sánchez-Gracia et al., 2009; Pelosi et al., 2014), the genus Nasonia thus seems to possess an exceptionally large OBP and CSP gene family. In accordance with the high number of OBPs and CSPs, the number of loci coding for ORs in $N v$ is also notably large compared to other insects (225 as compared to 170 in A. mellifera and 62 in D. melanogaster; Robertson and Wanner, 2006; Robertson et al., 2010). In accordance with the Nasonia lifestyle, although possessing 58 predicted GRs, no predicted carbon dioxide receptors have been found in $N v$ (Robertson et al., 2010).

The Nasonia OBPs, ORs, and GRs have not yet been functionally characterized. Neither the ORs detecting the different pheromone components nor the olfactory sensillae housing the pheromone sensing olfactory receptor neurons have been identified so far. The neurophysiological mechanisms underlying the stereospecific perception of chiral semiochemicals by insects are poorly understood. A comparative study of the Nasonia olfactory system offers therefore great opportunities to achieve major advances, because the species specificity of the chemical information is encoded by the chiral stereoisomers RSand RR-HDL which are perceived differentially by $N v$ and the other Nasonia species, respectively (Niehuis et al., 2013). The availability of whole genome sequences and annotated olfactory gene families for the Nasonia species will facilitate the application of molecular tools to unravel the mechanisms underlying the perception of a newly evolved chiral pheromone component. Hence, the Nasonia model system has the potential to enable important inferences on the molecular basis of enantioselective pheromone perception in insects.

\section{OUTLOOK}

On a mechanistic level, the chemical communication system of $N$. vitripennis is meanwhile one of the best understood in insects. The chemicals that have been identified and whose pheromonal function has been demonstrated experimentally include the three components of the male abdominal sex 
pheromone, the female-derived sex pheromone enabling male mate recognition, and the components of the oral male sex pheromone that induce the pheromone switch in females (see Table 1). Nevertheless, there are still gaps in our knowledge on the species' chemical ecology, concerning in particular the identification of the constituents of the oral sex pheromone that induce receptivity in females, the substances that induce the postmating receptivity switch, the chemical cues used by females to find and recognize adequate hosts, and the chemical messengers enabling females to distinguish between parasitized and nonparasitized hosts. More pronounced than in N. vitripennis are the gaps in our knowledge of the chemical ecology of the other three Nasonia species. The number of studies investigating the different species in a comparative approach, however, has grown in recent years revealing more and more differences in their behavioral strategies, their chemical communication and ecology.

In general, research in the field of chemical ecology has shifted during the last years from mere mechanistic approaches to more complex studies that investigate the evolution of chemical signals and their perception instead of their mere function, and, secondly, from male-female and dual-species interactions to approaches analyzing multi-species interactions (Raguso et al., 2015).

Together with the species' distributional patterns, the Nasonia genus forms an exceptional system for the study of the evolution of chemical signals and pre-zygotic reproductive isolation in general, and the evolution of pheromonal signals in particular. For example, the two sister species $\mathrm{Ng}$ and $\mathrm{No}$ occur in microsympatry in eastern North America and the two species are separated from the allopatric species $N$. longicornis in western North America (Figure 1). In a comparative approach within the Nasonia genus, it might thus be possible to discriminate between reproductive species characteristics that likely result from phylogenetic relatedness and species differences that likely evolved through natural selection caused by post-zygotic reproductive isolation. This is particularly interesting, as males of No appear to produce significantly smaller amounts of HDL indicating that No males do not rely on sex pheromone markings during mate acquisition (Diao et al., 2016). Furthermore, the genes encoding the epimerization of RS- to RR-HDL in $N v$ males are known (Niehuis et al., 2013; Ruther et al., 2016), and switching off RR-HDL production in $N v$ using RNA interference or the CRISPR/Cas 9 system (Li et al., 2017) combined with behavioral observations and fitness measurements in multiparasitized hosts might give valuable insights into the selection pressures that led to the evolution of RR-HDL in $N v$.

So far, it is not fully understood, how the male abdominal sex pheromone of Nasonia has evolved and how the evolution was driven by selection pressures imposed by other co-occurring species. This question could be further addressed by investigating in more detail the differences and similarities in the pheromone communication and behavior of species which occur in (micro)sympatry with Nasonia such as Muscidifurax, Spalangia or Pachycrepoideus (Rueda and Axtell, 1985; Rueda et al., 1997). In this context, the genera Urolepis and Trichomalopsis will be of particular interest, because they are the closest known relatives of Nasonia and have been suggested to form a monophyletic taxon with Nasonia, the so-called "Nasonia group" (Burks, 2009). Males of the only two species of these genera studied so far, $T$. sarcophagae, and $U$. rufipes, produce male abdominal sex pheromones. However, while the pheromone composition of $T$. sarcophagae equals the pheromones of $\mathrm{Ng}, \mathrm{Nl}$, and $\mathrm{No}$ (Niehuis et al., 2013), $U$. rufipes males use the monoterpenoid 2,6dimethyl-7-octen-1,6-diol to attract virgin females (Ruther et al., 2019). The evolutionary pressures underlying this unusual switch between fatty acid and isoprenoid metabolism in the Nasonia group deserve further research activities in the future.

The exceptional role of fatty acid-derived compounds in the intraspecific communication of Nasonia raises the question whether these species are capable of synthesizing fatty acids de novo from nutritional carbohydrates. While the fatty acid biosynthetic machinery is highly conserved in most taxa it has been suggested to be lost in most parasitic wasps including $N$. vitripennis. It has been argued that parasitoid wasps get sufficient lipids from their host resulting in a loss of lipogenesis during evolution due to environmental compensation (Visser et al., 2010, 2012). However, in many species, the lack of lipogenesis has been concluded from experiments involving rather unsubtle techniques such as gravimetry or colorimetry and re-investigation with stable isotope labeling techniques will be necessary to consolidate the lack of lipogenesis in Nasonia and other parasitic wasps.

A similarly important but still unanswered question in chemical ecology concerns the molecular mechanisms underlying the stereoselective perception of chiral pheromone components (Lassance and Löfstedt, 2013). The evolution of the additional male sex pheromone component RR-HDL in $N v$ is accompanied by the females' stereoselective perception of RS- and RR-HDL. The comparative characterization of ORs detecting RS-HDL and RR-HDL in Nasonia species could thus help getting novel insights into the role of chirality in the evolution of chemical communication in insects.

Finally, during the past decades, Nasonia has proven to be an excellent lab animal, while laborious field studies with these tiny insects are rare (Grillenberger et al., 2009a,b). Hence, one of the major challenges of future Nasonia research will be the step from well-controlled lab experiments and microcosm approaches to field studies investigating chemical communication and orientation of the Nasonia species in the wild. The ever-expanding techniques available for Nasonia in chemical ecology and genetics, combined with behavioral ecology and some already existing experience with field studies put this genus in the prime position to solve these questions.

\section{AUTHOR CONTRIBUTIONS}

Both authors conceptualized the paper and approved the final version for publication. MM wrote the first draft and revised the manuscript. JR reviewed and edited the manuscript.

\section{ACKNOWLEDGMENTS}

Funding was provided by the Deutsche Forschungsgemeinschaft (DFG) grant number Ru-717-10/2. 


\section{REFERENCES}

Abdel-Latief, M., Garbe, L. A., Koch, M., and Ruther, J. (2008). An epoxide hydrolase involved in the biosynthesis of an insect sex attractant and its use to localize the production site. Proc. Natl. Acad. Sci. U.S.A. 105, 8914-8919. doi: 10.1073/pnas.0801559105

Barrass, R. (1960). The courtship behaviour of Mormoniella vitripennis walk. (Hymenoptera, Pteromalidae). Behaviour 15, 185-208. doi: $10.1163 / 156853960 \times 00223$

Barrass, R. (1961). A quantitative study of the behaviour of the male Mormoniella vitripennis (Walker) (Hymenoptera, Pteromalidae) towards two constant stimulus-situations. Behaviour 18, 288-311. doi: 10.1163/156853961X00178

Barrass, R. (1969). Preening and abdomen dipping by the male Mormoniella vitripennis (Walker) (Hymenoptera, Pteromalidae) after courtship. Behaviour 35, 304-312. doi: 10.1163/156853969X00279

Bennett, G. F., and Whitworth, T. L. (1992). Host, nest, and ecological relationships of species of Protocalliphora (Diptera: Calliphoridae). Can. J. Zool. 70, 51-61. doi: $10.1139 / \mathrm{z} 92-008$

Bien, T., Gadau, J., Schnapp, A., Yew, J. Y., Sievert, C., and Dreisewerd, K. (2019). Detection of very long-chain hydrocarbons by laser mass spectrometry reveals novel species-, sex-, and age-dependent differences in the cuticular profiles of three Nasonia species. Anal. Bioanal. Chem. 411, 2981-2993. doi: 10.1007/s00216-019-01736-y

Birch, M., and Hefetz, A. (1987). Extrusible organs in male moths and their role in courtship behavior. Bull. Entomol. Soc. Am. 33, 222-229.

Blaul, B., and Ruther, J. (2011). How parasitoid females produce sexy sons: a causal link between oviposition preference, dietary lipids and mate choice in Nasonia. Proc. R. Soc. B 278, 3286-3293. doi: 10.1098/rspb.2011.0001

Blaul, B., and Ruther, J. (2012). Body size influences male pheromone signals but not the outcome of mating contests in Nasonia vitripennis. Anim. Behav. 84, 1557-1563. doi: 10.1016/j.anbehav.2012.10.001

Blaul, B., Steinbauer, R., Merkl, P., Merkl, R., Tschochner, H., and Ruther, J. (2014). Oleic acid is a precursor of linoleic acid and the male sex pheromone in Nasonia vitripennis. Insect Biochem. Mol. Biol. 51, 33-40. doi: 10.1016/j.ibmb.2014.05.007

Blomquist, G. J., and Bagnères, A.-G. (2010). Insect Hydrocarbons. Biology, Biochemistry, and Chemical Ecology. Cambridge: Cambridge University Press. doi: $10.1017 /$ CBO9780511711909

Bordenstein, S. R., O’Hara, F. P., and Werren, J. H. (2001). Wolbachia-induced incompatibility precedes other hybrid incompatibilities in Nasonia. Nature 409, 707-710. doi: 10.1038/35055543

Boulton, R. A., and Shuker, D. M. (2015). A sex allocation cost to polyandry in a parasitoid wasp. Biol. Lett. 11:20150205. doi: 10.1098/rsbl.2015.0205

Brandstetter, B., and Ruther, J. (2016). An insect with a delta-12 desaturase, the jewel wasp Nasonia vitripennis, benefits from nutritional supply with linoleic acid. Sci. Nat. 103:40. doi: 10.1007/s00114-016-1365-0

Breeuwer, J. A., and Werren, J. H. (1990). Microorganisms associated with chromosome destruction and reproductive isolation between two insect species. Nature 346, 558-560. doi: 10.1038/346558a0

Buckner, J. S. (1993). "Cuticular polar lipids of insects," in Insect Lipids. Chemistry, Biochemistry and Biology, eds D. W. Stanley-Samuelson and D. R. Nelson (Lincoln, NE; London: University of Nebraska Press), 227-270.

Buellesbach, J., Gadau, J., Beukeboom, L. W., Echinger, F., Raychoudhury, R., Werren, J. H., et al. (2013). Cuticular hydrocarbon divergence in the jewel wasp Nasonia: evolutionary shifts in chemical communication channels? J. Evol. Biol. 26, 2467-2478. doi: 10.1111/jeb.12242

Buellesbach, J., Greim, C., Raychoudhury, R., and Schmitt, T. (2014). Asymmetric assortative mating behaviour reflects incomplete pre-zygotic isolation in the Nasonia species complex. Ethology 120, 1-10. doi: 10.1111/eth.12250

Buellesbach, J., Vetter, S. G., and Schmitt, T. (2018). Differences in the reliance on cuticular hydrocarbons as sexual signaling and species discrimination cues in parasitoid wasps. Front. Zool. 15:22. doi: 10.1186/s12983-018-0263-Z

Burke, C. J., Huetteroth, W., Owald, D., Perisse, E., Krashes, M. J., Das, G., et al. (2012). Layered reward signalling through octopamine and dopamine in Drosophila. Nature 492, 433-437. doi: 10.1038/nature11614

Burks, R. A. (2009). Phylogenetics of Pteromalidae and Eulophidae (Hymenoptera: Chalcidoidea) with a Study of Cranial Bridges in Chalcidoidea. (dissertation) UC Riverside. ProQuest ID: Burks_ucr_0032D_10128. Merritt ID: ark:/13030/m56d5wts. Retrieved from: https://escholarship.org/uc/item/ 372001tw (accessed May 14, 2019)

Burton-Chellew, M. N., Beukeboom, L. W., West, S. A., and Shuker, D. M. (2007a). Laboratory evolution of polyandry in the parasitoid wasp Nasonia vitripennis. Anim. Behav. 74, 1147-1154. doi: 10.1016/j.anbehav.2006.09.028

Burton-Chellew, M. N., Koevoets, T., Grillenberger, B. K., Sykes, E. M., Underwood, S. L., Bijlsma, K., et al. (2008). Facultative sex ratio adjustment in natural populations of wasps: cues of local mate competition and the precision of adaptation. Am. Nat. 172, 393-404. doi: 10.1086/589895

Burton-Chellew, M. N., Sykes, E. M., Patterson, S., Shuker, D. M., and West, S. A. (2007b). The cost of mating and the relationship between body size and fitness in males of the parasitoid wasp Nasonia vitripennis. Evol. Ecol. Res. 9, 921-934.

Butenandt, A., Beckmann, R., Stamm, D., and Hecker, E. (1959). Über den SexualLockstoff des Seidenspinners Bombyx mori. Reindarstellung und Konstitution. Z. Naturforschg. 14b, 283-284.

Cônsoli, F. L., Williams, H. J., Vinson, S. B., Matthews, R. W., and Cooperband, M. F. (2002). trans-Bergamotenes-Male pheromone of the ectoparasitoid Melittobia digitata. J. Chem. Ecol. 28, 1675-1689. doi: 10.1023/A:1019940932605

Cardé, R., and Baker, T. (1984). Chemical Ecology of Insects. Boston, MA: Springer. Carlson, D. A., Geden, C. J., and Bernier, U. R. (1999). Identification of pupal exuviae of Nasonia vitripennis and Muscidifurax raptorellus parasitoids using cuticular hydrocarbons. Biol. Contr. 15, 97-106. doi: 10.1006/bcon.1999.0708

Chirault, M., van de Zande, L., Hidalgo, K., Chevrier, C., Bressac, C., and Lécureuil, C. (2016). The spatio-temporal partitioning of sperm by males of the prospermatogenic parasitoid Nasonia vitripennis is in line with its gregarious lifestyle. J. Insect Physiol. 91-92, 10-17. doi: 10.1016/j.jinsphys.2016.06.002

Cooper, J. L., and King, B. H. (2015). Substrate-borne marking in the parasitoid wasp Urolepis rufipes (Hymenoptera: Pteromalidae). Environ. Entomol. 44, 680-688. doi: 10.1093/ee/nvv017

Danneels, E. L., Rivers, D. B., and de Graaf, D. C. (2010). Venom proteins of the parasitoid wasp Nasonia vitripennis: recent discovery of an untapped pharmacopee. Toxins 2, 494-516. doi: 10.3390/toxins2040494

Darling, D., and Werren, J. H. (1990). Biosystematics of Nasonia (Hymenoptera: Pteromalidae): two new species reared from birds' nests in North America. Ann. Entomol. Soc. Am. 83, 352-370. doi: 10.1093/aesa/83.3.352

Davies, I., and King, P. E. (1975). The structure of the rectal papilla in a parasitoid hymenopteran Nasonia vitripennis (Walker) (Hymenoptera Pteromalidae). Cell Tissue Res. 161, 413-419. doi: 10.1007/BF00220008

de Graaf, D. C., Aerts, M., Brunain, M., Desjardins, C. A, Jacobs, F. J., Werren, J. H., et al. (2010). Insights into the venom composition of the ectoparasitoid wasp Nasonia vitripennis from bioinformatic and proteomic studies. Insect Molec. Biol. 19 (Suppl. 1), 11-26. doi: 10.1111/j.1365-2583.2009.00914.x

Denno, R. F., and Cothran, W. R. (1976). Competitive interactions and ecological strategies of sarcophagid and calliphorid flies inhabiting rabbit carrion. Ann. Entomol. Soc. Am. 69, 109-113. doi: 10.1093/aesa/69.1.109

Desjardins, C. A., Perfectti, F., Bartos, J. D., Enders, L. S., and Werren, J. H. (2010). The genetic basis of interspecies host preference differences in the model parasitoid Nasonia. Heredity 104, 270-277. doi: 10.1038/hdy.2009.145

Diao, W., Mousset, M., Horsburgh, G. J., Vermeulen, C. J., Johannes, F., van de Zande, L., et al. (2016). Quantitative trait locus analysis of mating behavior and male sex pheromones in Nasonia wasps. G3 6, 1549-1562. doi: $10.1534 / \mathrm{g} 3.116 .029074$

Dicke, M. (2009). Behavioural and community ecology of plants that cry for help. Plant Cell Environ. 32, 654-665. doi: 10.1111/j.1365-3040.2008. 01913.x

Drapeau, M. D., and Werren, J. H. (1999). Differences in mating behaviour and sex ratio between three sibling species of Nasonia. Evol. Ecol. Res. 1, 223-234.

Edwards, R. L. (1954). The host-finding and oviposition behaviour of Mormoniella vitripennis (Walker) (Hym., Pteromalidae), a parasite of muscoid flies. Behaviour 7, 88-112. doi: 10.1163/156853955X00049

Eliyahu, D., Nojima, S., Capracotta, S. S., Comins, D. L., and Schal, C. (2008). Identification of cuticular lipids eliciting interspecific courtship in the German cockroach, Blattella germanica. Naturwissenschaften 95, 403-412. doi: 10.1007/s00114-007-0339-7

Fatouros, N. E., Dicke, M., Mumm, R., Meiners, T., and Hilker, M. (2008). Foraging behavior of egg parasitoids exploiting chemical information. Behav. Ecol. 19, 677-689. doi: 10.1093/beheco/arn011 
Frederickx, C., Dekeirsschieter, J., Verheggen, F. J., and Haubruge, E. (2013). Hosthabitat location by the parasitoid, Nasonia vitripennis Walker (Hymenoptera: Pteromalidae). J. Forensic Sci. 59, 242-249. doi: 10.1111/1556-4029.12267

Gadau, J., Niehuis, O., Peire, A., Werren, J. H., Baudry, E., and Beukeboom, L. W. (2008). "The jewel wasp-Nasonia," in Genome Mapping and Genomics in Arthropods. Genome Mapping and Genomics in Animals, Vol. 1, eds. H. Wayne and C. Kole (Berlin; Heidelberg: Springer), 27-41. doi: 10.1007/978-3-540-73833-6_3

Geuverink, E., Gerritsma, S., Pannebakker, B., and Beukeboom, L. (2009). A role for sexual conflict in the evolution of reproductive traits in Nasonia wasps? Anim. Biol. 59, 417-434. doi: 10.1163/157075509X12499949744261

Gibbs, A. G. (1998). Water-proofing properties of cuticular lipids. Am. Zool. 38, 471-482. doi: $10.1093 / \mathrm{icb} / 38.3 .471$

Giesbers, M. C. W. G., Gerritsma, S., Buellesbach, J., Diao, W., Pannebakker, B. A., van de Zande, L., et al. (2013). "Prezygotic isolation in the parasitoid wasp genus Nasonia," in Speciation: Natural Processes, Genetics and Biodiversity, ed M. Pawel (New York, NY: Nova Science Publishers, Inc.), 165-191.

Giesbers, M. C. W. G., Pannebakker, B. A., van de Zande, L., and Beukeboom, L. (2016). Within-host-mating in the Nasonia genus is largely dependent on male behavior. Genetics of Reproductive Behaviour in Nasonia (dissertation). ed M. C. W. G. Giesbers. Groningen: University of Groningen.

Goubault, M., Batchelor, T. P., Linforth, R. S., Taylor, A. J., and Hardy, I. C. W. (2006). Volatile emission by contest losers revealed by real-time chemical analysis. Proc. R. Soc. B. 273, 2853-2859. doi: 10.1098/rspb.2006.3655

Greenfield, M. D. (1981). Moth sex pheromones: an evolutionary perspective. Fla. Entomol. 64, 4-17. doi: 10.2307/3494597

Grillenberger, B. K., Gadau, J., Bijlsma, R., van de Zande, L., and Beukeboom, L. W. (2009a). Female dispersal and isolation-by-distance of Nasonia vitripennis populations in a local mate competition context. Entomol. Exp. Appl. 132, 147-154. doi: 10.1111/j.1570-7458.2009.00881.x

Grillenberger, B. K., Koevoets, T., Burton-Chellew, M. N., Sykes, E. M., Shuker, D. M., van de Zande, L., et al. (2008). Genetic structure of natural Nasonia vitripennis populations: validating assumptions of sex-ratio theory. Mol. Ecol. 17, 2854-2864. doi: 10.1111/j.1365-294X.2008.03800.x

Grillenberger, B. K., van de Zande, L., Bijlsma, R., Gadau, J., and Beukeboom, L. W. (2009b). Reproductive strategies under multiparasitism in natural populations of the parasitoid wasp Nasonia (Hymenoptera). J. Evol. Biol. 22, 460-470. doi: 10.1111/j.1420-9101.2008.01677.x

Groothuis, J., and Smid, H. M. (2017). Nasonia parasitic wasps escape from Haller's rule by diphasic, partially isometric brain-body size scaling and selective neuropil adaptations. Brain Behav. Evol. 90, 243-254. doi: 10.1159/000 480421

Hammer, M., and Menzel, R. (1998). Multiple sites of associative odor learning as revealed by local brain microinjections of octopamine in honeybees. Learn. Mem. 5, 146-156.

Heimpel, G. E., and de Boer, J. G. (2008). Sex determination in the Hymenoptera. Ann. Rev. Entomol. 53, 209-230. doi: 10.1146/annurev.ento.53.103106. 093441

Hoedjes, K. M., Kralemann, L. E. M., van Vugt, J. J. F., a., Vet, L. E. M., and Smid, H. M. (2014). Unravelling reward value: the effect of host value on memory retention in Nasonia parasitic wasps. Anim. Behav. 96, 1-7. doi: 10.1016/j.anbehav.2014.07.013

Hoedjes, K. M., Kruidhof, H. M., Huigens, M. E., Dicke, M., Vet, L. E., and Smid, H. M. (2011). Natural variation in learning rate and memory dynamics in parasitoid wasps: opportunities for converging ecology and neuroscience. Proc. R. Soc. B. 278, 889-897. doi: 10.1098/rspb.2010.2199

Hoedjes, K. M., and Smid, H. M. (2014). Natural variation in long-term memory formation among Nasonia parasitic wasp species. Behav. Processes 105, 40-45. doi: 10.1016/j.beproc.2014.02.014

Hoedjes, K. M., Steidle, J. L., Werren, J. H., Vet, L. E., and Smid, H. M. (2012). High-throughput olfactory conditioning and memory retention test show variation in Nasonia parasitic wasps. Genes Brain Behav. 11, 879-887. doi: 10.1111/j.1601-183X.2012.00823.x

Holmes, H. (1972). Genetic evidence for fewer progeny and a higher percent males when Nasonia vitripennis oviposits in previously parasitized hosts. Entomophaga 17, 79-88. doi: 10.1007/BF02371075

Holmes, H. (1974). Patterns of sperm competition in Nasonia vitripennis. Can. J. Genet. Cytol. 16, 789-795. doi: 10.1139/g74-085
Howard, R. W., and Blomquist, G. J. (2005). Ecological, behavioral, and biochemical aspects of insect hydrocarbons. Ann. Rev. Entomol. 50, 371-393. doi: 10.1146/annurev.ento.50.071803.130359

Ivens, A. B., Shuker, D. M., Beukeboom, L. W., and Pen, I. (2009). Host acceptance and sex allocation of Nasonia wasps in response to conspecifics and heterospecifics. Proc. R. Soc. B.y 276, 3663-3669. doi: 10.1098/rspb.2009.0977

Jachmann, F., and van den Assem, J. (1996). A causal ethological analysis of the courtship behaviour of an insect (the parasitic wasp Nasonia vitripennis, Hym., Pteromalidae). Behaviour 133, 1051-1075. doi: 10.1163/1568 53996X00594

Johansson, B. G., and Jones, T. M. (2007). The role of chemical communication in mate choice. Biol. Rev. Camb. Philos. Soc. 82, 265-289. doi: 10.1111/j.1469-185X.2007.00009.x

Jones, W. D., Cayirlioglu, P., Kadow, I. G., and Vosshall, L. B. (2007). Two chemosensory receptors together mediate carbon dioxide detection in Drosophila. Nature 445, 86-90. doi: 10.1038/nature05466

Kasper, J., Mumm, R., and Ruther, J. (2012). The composition of carcass volatile profiles in relation to storage time and climate conditions. Forensic Sci. Int. 223, 64-71. doi: 10.1016/j.forsciint.2012.08.001

Kaupp, U. B. (2010). Olfactory signalling in vertebrates and insects: differences and commonalities. Nat. Rev. Neurosci. 11, 188-200. doi: 10.1038/nrn2789

Keppner, E. M., Prang, M., Engel, K. C., Ayasse, M., Stökl, J., and Steiger, S. (2017). Beyond cuticular hydrocarbons: chemically mediated mate recognition in the subsocial burying beetle Nicrophorus vespilloides. J. Chem. Ecol. 43, 84-93. doi: 10.1007/s10886-016-0806-8

King, B. H. (1993). Flight activity in the parasitoid wasp Nasonia vitripennis (Hymenoptera: Pteromalidae). J. Insect Behav. 6, 313-321. doi: 10.1007/BF01048112

King, B. H., Grimm, K., and Reno, H. (2000). Effects of mating on female locomotor activity in the parasitoid wasp Nasonia vitripennis (Hymenoptera: Pteromalidae). Environ. Entomol. 29, 927-933. doi: 10.1603/0046-225X-29.5.927

King, B. H., and Skinner, S. W. (1991). Proximal mechanisms of the sex ratio and clutch size responses of the wasp Nasonia vitripennis to parasitized hosts. Anim. Behav. 42, 23-32. doi: 10.1016/S0003-3472(05)80602-5

King, P. E., and Rafai, J. (1970). Host discrimination in a gregarious parasitoid Nasonia vitripennis (Walker) (Hymenoptera: Pteromalidae). J. Exp. Biol. $53,245-254$

Kühbandner, S., and Ruther, J. (2015). Solid phase micro-extraction (SPME) with in situ transesterification: an easy method for the detection of nonvolatile fatty acid derivatives on the insect cuticle. J. Chem. Ecol. 41, 584-592. doi: 10.1007/s10886-015-0592-8

Kühbandner, S., Sperling, S., Mori, K., and Ruther, J. (2012). Deciphering the signature of cuticular lipids with contact sex pheromone function in a parasitic wasp. J. Exp. Biol. 215, 2471-2478. doi: 10.1242/jeb.071217

Landolt, P. J. (1997). Sex attractant and aggregation pheromones of male phytophagous insects. Am. Entomol. 43, 12-22. doi: 10.1093/ae/43.1.12

Lassance, J.-M., and Löfstedt, C. (2013). Chemical evolution: a jewel sheds light on signal evolution. Curr. Biol. 23, R346-R348. doi: 10.1016/j.cub.2013.03.055

Lenschow, M., Cordel, M., Pokorny, T., Mair, M. M., Hofferberth, J., and Ruther, J. (2018). The post-mating switch in the pheromone response of Nasonia females is mediated by dopamine and can be reversed by appetitive learning. Front. Behav. Neurosci. 12:14. doi: 10.3389/fnbeh.2018.00014

Leonard, J. E., and Boake, C. R. B. (2006). Site-dependent aggression and mating behaviour in three species of Nasonia (Hymenoptera: Pteromalidae). Anim. Behav. 71, 641-647. doi: 10.1016/j.anbehav.2005.07.010

Leonard, J. E., and Boake, C. R. B. (2008). Associations between male courtship and female polyandry in three species of wasp, Nasonia (Hymenoptera: Pteromalidae). Anim. Behav. 76, 637-647. doi: 10.1016/j.anbehav.2008.04.013

Li, M., Au, L. Y. C., Douglah, D., Chong, A., White, B. J., Ferree, P. M., et al. (2017). Generation of heritable germline mutations in the jewel wasp Nasonia vitripennis using CRISPR/Cas9. Sci. Rep. 7:901. doi: 10.1038/s41598-017-00990-3

Liou, L. W., and Price, T. D. (1994). Speciation by reinforcement of premating isolation. Evolution 48, 1451-1459. doi: 10.1111/j.1558-5646. 1994.tb02187.x

Lockey, K. H. (1988). Lipids of the insect cuticle: origin, composition and function. Comp. Biochem. Physiol. B 89, 595-645. doi: 10.1016/0305-0491(88)90305-7 
Lynch, J. A. (2015). The expanding genetic toolbox of the wasp Nasonia vitripennis and its relatives. Genetics 199, 897-904. doi: 10.1534/genetics.112.147512

Lynch, J. A., and Desplan, C. (2006). A method for parental RNA interference in the wasp Nasonia vitripennis. Nat. Protoc. 1, 486-494. doi: $10.1038 /$ nprot. 2006.70

Mair, M. M., Kmezic, V., Huber, S., Pannebakker, B. A., and Ruther, J. (2017). The chemical basis of mate recognition in two parasitoid wasp species of the genus Nasonia. Entomol. Exp. Appl. 164, 1-15. doi: 10.1111/eea.12589

Mair, M. M., and Ruther, J. (2018). Territoriality and behavioural strategies at the natal host patch differ in two microsympatric Nasonia species. Anim. Behav. 143, 113-129. doi: 10.1016/j.anbehav.2018.07.015

Mair, M. M., Seifert, N., and Ruther, J. (2018). Previous interspecific courtship impairs female receptivity to conspecifics in the parasitoid wasp Nasonia longicornis but not in N. vitripennis. Insects 9:112. doi: 10.3390/insects9030112

Martinson, E. O., Martinson, V. G., Edwards, R., Mrinalini, and Werren, J. H. (2016). Laterally transferred gene recruited as a venom in parasitoid wasps. Mol. Biol. Evol. 33, 1042-1052. doi: 10.1093/molbev/msv348

Martinson, E. O., Mrinalini, Kelkar, Y. D., Chang, C.-H., and Werren, J. H. (2017). The evolution of venom by co-option of single-copy genes. Curr. Biol. 27, 2007-2013. doi: 10.1016/j.cub.2017.05.032

Martinson, E. O., Siebert, A. L., He, M., Kelkar, Y. D., Doucette, L. A., and Werren, J. H. (2019). Evaluating the evolution and function of the dynamic Venom $Y$ protein in ectoparasitoid wasps. Insect Mol. Biol. doi: 10.1111/imb.12565. [Epub ahead of print].

Martinson, E. O., Wheeler, D., Wright, J., Mrinalini, Siebert, A. L., and Werren, J. H. (2014). Nasonia vitripennis venom causes targeted gene expression changes in its fly host. Mol. Ecol. 23, 5918-5930. doi: 10.1111/mec.12967

Matsumoto, Y., Matsumoto, C.-S., Wakuda, R., Ichihara, S., and Mizunami, M. (2015). Roles of octopamine and dopamine in appetitive and aversive memory acquisition studied in olfactory conditioning of maxillary palpi extension response in crickets. Front. Behav. Neurosci. 9:230. doi: 10.3389/fnbeh.2015.00230

Menzel, R., and Muller, U. (1996). Learning and memory in honeybees: from behavior to neural substrates. Ann. Rev. Neurosci. 19, 379-404. doi: 10.1146/annurev.ne.19.030196.002115

Miko, I., and Deans, A. (2014). The mandibular gland in Nasonia vitripennis (Hymenoptera: Pteromalidae). bioRxiv 006569. doi: 10.1101/006569

Mohamed, M. A., and Coppel, H. C. (1987). Pheromonal basis for aggregation behavior of parasitoids of the gypsy moth: Brachymeria intermedia (Nees) and Brachymeria lasus (Walker) (Hymenoptera: Chalcididae). J. Chem. Ecol. 13, 1385-1393. doi: 10.1007/BF01012285

Mrinalini, Siebert, A. L., Wright, J., Martinson, E., Wheeler, D., and Werren, J. H. (2015). Parasitoid venom induces metabolic cascades in fly hosts. Metabolomics 11, 350-366. doi: 10.1007/s11306-014-0697-z

Niehuis, O., Buellesbach, J., Gibson, J. D., Pothmann, D., Hanner, C., Mutti, N. S., et al. (2013). Behavioural and genetic analyses of Nasonia shed light on the evolution of sex pheromones. Nature 494, 345-348. doi: 10.1038/nature 11838

Niehuis, O., Büllesbach, J., Judson, A. K., Schmitt, T., Gadau, J., (2010). Genetics of cuticular hydrocarbon differences between males of the parasitoid wasps Nasonia giraulti and Nasonia vitripennis. Heredity 107, 1-10. doi: 10.1038/hdy.2010.157

Nufio, C. R., and Papaj, D. R. (2001). Host marking behavior in phytophagous insects and parasitoids. Entomol. Exp. Appl. 99, 273-293. doi: 10.1046/j.1570-7458.2001.00827.x

Oakeshott, J. G., Johnson, R. M., Berenbaum, M. R., Ranson, H., Cristino, A., and Claudianos, C. (2010). Metabolic enzymes associated with xenobiotic and chemosensory responses in Nasonia vitripennis. Ins. Mol. Biol. 19, 147-163. doi: 10.1111/j.1365-2583.2009.00961.x

Oliw, E. H. (1994). Oxygenation of polyunsaturated fatty acids by cytochrome P450 monooxygenates. Prog. Lipid Res. 33, 329-354. doi: 10.1016/0163-7827(94)90029-9

Pelosi, P., Iovinella, I., Felicioli, A., and Dani, F. R. (2014). Soluble proteins of chemical communication: an overview across. Front. Physiol. 5:320. doi: $10.3389 /$ fphys. 2014.00320

Peters, R. S. (2011). Two ways of finding a host: a specialist and a generalist parasitoid species (Hymenoptera: Chalcidoidea: Pteromalidae). Eur. J. Entomol. 108, 565-573. doi: 10.14411/eje.2011.073
Pichersky, E., and Gershenzon, J. (2002). The formation and function of plant volatiles: perfumes for pollinator attraction and defense. Curr. Opin. Plant Biol. 5, 237-243. doi: 10.1016/S1369-5266(02)00251-0

Quicke, D. (1997). Parasitic Wasps. London: Chapman and Hall.

Raguso, R. A., Agrawal, A. A., Douglas, A. E., Jander, G., Kessler, A., Poveda, K., et al. (2015). The raison d'être of chemical ecology. Ecology 96, 617-630. doi: 10.1890/14-1474.1

Rantala, M. J., Vainikka, A., and Kortet, R. (2003). The role of juvenile hormone in immune function and pheromone production trade-offs: a test of the immunocompetence handicap principle. Proc. R. Soc. B. 270, 2257-2261. doi: $10.1098 / \mathrm{rspb} .2003 .2472$

Ratcliffe, N., and King, P. E. (1967). The "venom" system of Nasonia vitripennis (Walker) (Hymenoptera: Pteromalidae). Physiol. Entomol. 42, 49-61. doi: 10.1111/j.1365-3032.1967.tb01002.x

Raychoudhury, R., Desjardins, C. A., Buellesbach, J., Loehlin, D. W., Grillenberger, B. K., Beukeboom, L., et al. (2010a). Behavioral and genetic characteristics of a new species of Nasonia. Heredity 104, 278-288. doi: 10.1038/hdy.2009.147

Raychoudhury, R., Grillenberger, B. K., Gadau, J., Bijlsma, R., van de Zande, L., Werren, J. H., et al. (2010b). Phylogeography of Nasonia vitripennis (Hymenoptera) indicates a mitochondrial-Wolbachia sweep in North America. Heredity 104, 318-326. doi: 10.1038/hdy.2009.160

Renwick, J. A. (1989). Chemical ecology of oviposition in phytophagous insects. Experientia 45, 223-228. doi: 10.1007/BF01951807

Rivero, A., and West, S. (2005). The costs and benefits of host feeding in parasitoids. Anim. Behav. 69, 1293-1301. doi: 10.1016/j.anbehav.2004.10.008

Rivero, A., and West, S. A. (2002). The physiological costs of being small in a parasitic wasp. Evol. Ecol. Res. 4, 407-420.

Rivers, D. B., and Denlinger, D. L. (1994a). Developmental fate of the flesh fly, Sarcophaga bullata, envenomated by the pupal ectoparasitoid, Nasonia vitripennis. J. Insect Physiol. 40, 121-127. doi: 10.1016/0022-1910(94)90083-3

Rivers, D. B., and Denlinger, D. L. (1994b). Redirection of metabolism in the flesh fly, Sarcophaga bullata, following envenomation by the ectoparasitoid Nasonia vitripennis and correlation of metabolic effects with the diapause status of the host. J. Insect Physiol. 40, 207-215. doi: 10.1016/0022-1910(94)90044-2

Rivers, D. B., and Denlinger, D. L. (1995a). Fecundity and development of the ectoparasitic wasp Nasonia vitripennis are dependent on host quality. Entomol. Exp. Appl. 76, 15-24. doi: 10.1111/j.1570-7458.1995.tb01942.x

Rivers, D. B., and Denlinger, D. L. (1995b). Venom-induced alterations in fly lipid metabolism and its impact on larval development of the ectoparasitoid Nasonia vitripennis (Walker) (Hymenoptera: Pteromalidae). J. Invertebr. Pathol. 66, 104-110. doi: 10.1006/jipa.1995.1071

Rivers, D. B., Hink, W. F., and Denlinger, D. L. (1993). Toxicity of the venom from Nasonia vitripennis (Hymenoptera: Pteromalidae) toward fly hosts, nontarget insects, different developmental stages, and cultured insect cells. Toxicon 31, 755-765. doi: 10.1016/0041-0101(93)90381-R

Rivers, D. B., Rocco, M. M., and Frayha, A. R. (2002a). Venom from the ectoparasitic wasp Nasonia vitripennis increases $\mathrm{Na}^{+}$influx and activates phospholipase $\mathrm{C}$ and phospholipase $\mathrm{A}_{2}$ dependent signal transduction pathways in cultured insect cells. Toxicon 40, 9-21. doi: 10.1016/S0041-0101(01)00132-5

Rivers, D. B., Ruggiero, L., and Hayes, M. (2002b). The ectoparasitic wasp Nasonia vitripennis (Walker) (Hymenoptera: Pteromalidae) differentially affects cells mediating the immune response of its flesh fly host, Sarcophaga bullata Parker (Diptera: Sarcophagidae). J. Insect Physiol. 48, 1053-1064. doi: 10.1016/S0022-1910(02)00193-2

Rivers, D. B., Uckan, F., and Ergin, E. (2006). Characterization and biochemical analyses of venom from the ectoparasitic wasp Nasonia vitripennis (Walker) (Hymenoptera: Pteromalidae). Arch. Insect Biochem. Physiol 61, 24-41. doi: $10.1002 /$ arch.20094

Rivers, D. B., and Yoder, J. A. (1996). Site-specific effects of parasitism on water balance and lipid content of the parasitic wasp Nasonia vitripennis (Hymenoptera: Pteromalidae). Eur. J. Entomol. 93, 75-82.

Robertson, H. M., Gadau, J., and Wanner, K. W. (2010). The insect chemoreceptor superfamily of the parasitoid jewel wasp Nasonia vitripennis. Insect Mol. Biol. 19 (Suppl, 1), 121-136. doi: 10.1111/j.1365-2583.2009.00979.x

Robertson, H. M., and Wanner, K. W. (2006). The chemoreceptor superfamily in the honey bee, Apis mellifera: expansion of the odorant, but not gustatory, receptor family. Genome Res. 16, 1395-1403. doi: 10.1101/gr.5057506 
Rueda, L. M., and Axtell, R. C. (1985). Comparison of hymenopterous parasites of house fly, Musca domestica (Diptera: Muscidae), pupae in different livestock and poultry production systems. Environ. Entomol. 14, 217-222. doi: $10.1093 / \mathrm{ee} / 14.3 .217$

Rueda, L. M., Roh, P.-U., and Ryu, J. L. (1997). Pupal parasitoids (Hymenoptera: Pteromalidae) of filth flies (Diptera: Muscidae, Calliphoridae) breeding in refuse and poultry and livestock manure in South Korea. J. Med. Entomol. 34, 82-85. doi: $10.1093 /$ jmedent/34.1.82

Ruther, J. (2013). "Novel insights into pheromone-mediated communication in parasitic hymenopterans," in Chemical Ecology of Insect Parasitoids, eds. E. Wajnberg and S. Colazza (West Sussex, UK: John Wiley \& Sons), 112-144. doi: 10.1002/9781118409589.ch6

Ruther, J., Hagström, Å. K., Brandstetter, B., Hofferberth, J., Bruckmann, A., Semmelmann, F., et al. (2016). Epimerisation of chiral hydroxylactones by short-chain dehydrogenases/reductases accounts for sex pheromone evolution in Nasonia. Sci. Rep. 6, 34697. doi: 10.1038/srep34697

Ruther, J., and Hammerl, T. (2014). An oral male courtship pheromone terminates the response of Nasonia vitripennis females to the male-produced sex attractant. J. Chem. Ecol. 40, 56-62. doi: 10.1007/s10886-013-0372-2

Ruther, J., Matschke, M., Garbe, L. A., and Steiner, S. (2009). Quantity matters: male sex pheromone signals mate quality in the parasitic wasp Nasonia vitripennis. Proc. R. Soc. B 276, 3303-3310. doi: 10.1098/rspb.2009.0738

Ruther, J., McCaw, J., Böcher, L., Pothmann, D., and Putz, I. (2014). Pheromone diversification and age-dependent behavioural plasticity decrease interspecific mating costs in Nasonia. PLoS ONE 9:e89214. doi: 10.1371/journal.pone.0089214

Ruther, J., Stahl, L. M., Steiner, S., Garbe, L. A., and Tolasch, T. (2007). A male sex pheromone in a parasitic wasp and control of the behavioral response by the female's mating status. J. Exp. Biol. 210, 2163-2169. doi: 10.1242/jeb.02789

Ruther, J., and Steidle, J. L. M. (2000). Mites as matchmakers: semiochemicals from host-associated mites attract both sexes of the parasitoid Lariophagus distinguendus. J. Chem. Ecol. 26, 1205-1217. doi: 10.1023/A:1005484027559

Ruther, J., Steiner, S., and Garbe, L.-A. (2008). 4-Methylquinazoline is a minor component of the male sex pheromone in Nasonia vitripennis. J. Chem. Ecol. 34, 99-102. doi: 10.1007/s10886-007-9411-1

Ruther, J., Thal, K., Blaul, B., and Steiner, S. (2010). Behavioural switch in the sex pheromone response of Nasonia vitripennis females is linked to receptivity signalling. Anim. Behav. 80, 1035-1040. doi: 10.1016/j.anbehav. 2010.09.008

Ruther, J., Thal, K., and Steiner, S. (2011). Pheromone communication in Nasonia vitripennis: abdominal sex attractant mediates site fidelity of releasing males. J. Chem. Ecol. 37, 161-165. doi: 10.1007/s10886-010-9898-8

Ruther, J., Wittman, T., Grimm, C., Feichtner, F. S., Fleischmann, S., Kiermaier, J., et al. (2019). Male sex pheromone of the parasitoid wasp Urolepis rufipes demonstrates biosynthetic switch between fatty acid and isoprenoid metabolism within the Nasonia group. Front. Ecol. Evol. 7:26. doi: $10.3389 /$ fevo.2019.00026

Salerno, G., Iacovone, A., Carlin, S., Frati, F., Conti, E., and Anfora, G. (2012). Identification of sex pheromone components in Trissolcus brochymenae females. J. Insect Physiol. 58, 1635-1642. doi: 10.1016/j.jinsphys.2012.10.003

Sánchez-Gracia, A., Vieira, F. G., and Rozas, J. (2009). Molecular evolution of the major chemosensory gene families in insects. Heredity 103, 208-216. doi: 10.1038/hdy.2009.55

Schurmann, D., Collatz, J., Hagenbucher, S., Ruther, J., and Steidle, J. L., (2009). Olfactory host finding, intermediate memory and its potential ecological adaptation in Nasonia vitripennis. Naturwissenschaften 96, 383-391. doi: 10.1007/s00114-008-0490-9

Schurmann, D., Sommer, C., Schinko, A. P. B., Greschista, M., Smid, H., Steidle, J. L. M., et al. (2012). Demonstration of long-term memory in the parasitic wasp Nasonia vitripennis. Entomol. Exp. Appl. 143, 199-206. doi: 10.1111/j.1570-7458.2012.01253.x

Schwaerzel, M., Monastirioti, M., Scholz, H., Friggi-Grelin, F., Birman, S., and Heisenberg, M. (2003). Dopamine and octopamine differentiate between aversive and appetitive olfactory memories in Drosophila. J. Neurosci. 23, 10495-10502. doi: 10.1523/JNEUROSCI.23-33-10495.2003

Scott, D., Richmond, R. C., and Carlson, D. A. (1988). Pheromones exchanged during mating: a mechanism for mate assessment in Drosophila. Anim. Behav. 36, 1164-1173. doi: 10.1016/S0003-3472(88)80075-7
Semmelmann, F., Hofferberth, J., Ruther, J., and Sterner, R. (2019a). Mapping key amino acid residues for the epimerase efficiency and stereospecificity of the sex pheromone biosynthetic short-chain dehydrogenases/reductases of Nasonia. Sci. Rep. 9:330. doi: 10.1038/s41598-018-37200-7

Semmelmann, F., Kabeya, N., Malcicka, M., Bruckmann, A., Broschwitz, B., Straub, K., et al. (2019b). Functional characterisation of two $\Delta 12$ desaturases demonstrates targeted production of linoleic acid as pheromone precursor in Nasonia. J. Exp. Biol. 222:201038. doi: 10.1242/jeb.201038

Shuker, D. M., Pen, I., and West, S. A. (2006). Sex ratios under asymmetrical local mate competition in the parasitoid wasp Nasonia vitripennis. Behav. Ecol. 17, 345-352. doi: 10.1093/beheco/arj034

Shuker, D. M., and West, S. A. (2004). Information constraints and the precision of adaptation: sex ratio manipulation in wasps. Proc. Natl. Acad. Sci. U.S.A. 101, 10363-10367. doi: 10.1073/pnas.0308034101

Siebert, A. L., Wheeler, D., and Werren, J. H. (2015). A new approach for investigating venom function applied to venom calreticulin in a parasitoid wasp. Toxicon 107, 304-316. doi: 10.1016/j.toxicon.2015.08.012

Singer, T. L. (1998). Roles of hydrocarbons in the recognition systems of insects. Am. Zool. 405, 394-405. doi: 10.1093/icb/38.2.394

Slifer, E. H. (1969). Sense organs on the antenna of a parasitic wasp, Nasonia vitripennis (Hymenoptera, Pteromalidae). Biol. Bull. 136, 253-263. doi: $10.2307 / 1539818$

Stanley, D. (2006). Prostaglandins and other eicosanoids in insects: biological significance. Annu. Rev. Entomol. 51, 25-44. doi: 10.1146/annurev.ento.51.110104.151021

Steidle, J. L. M., and van Loon, J. J. A. (2002). "Chemoecology of parasitoid and predator oviposition behaviour," in Chemoecology of Insect Eggs and Egg Deposition, eds M. Hilker and T. Meiners (Berlin: Blackwell), 291-317. doi: 10.1002/9780470760253.ch11

Steiner, S., Hermann, N., and Ruther, J. (2006). Characterization of a femaleproduced courtship pheromone in the parasitoid Nasonia vitripennis. J. Chem. Ecol. 32, 1687-1702. doi: 10.1007/s10886-006-9102-3

Steiner, S., and Ruther, J. (2009a). How important is sex for females of a haplodiploid species under local mate competition? Behav. Ecol. 20, 570-574. doi: 10.1093/beheco/arp033

Steiner, S., and Ruther, J. (2009b). Mechanism and behavioral context of male sex pheromone release in Nasonia vitripennis. J. Chem. Ecol. 35, 416-421. doi: 10.1007/s10886-009-9624-6

Stökl, J., Dandekar, A.-T., and Ruther, J. (2014). High chemical diversity in a wasp pheromone: a blend of methyl 6-methylsalicylate, fatty alcohol acetates and cuticular hydrocarbons releases courtship behavior in the Drosophila parasitoid Asobara tabida. J. Chem. Ecol. 40, 159-168. doi: 10.1007/s10886-014-0378-4

Sullivan, B. T. (2002). Evidence for a sex pheromone in bark beetle parasitoid Roptrocerus xylophagorum. J. Chem. Ecol. 28, 1045-1063. doi: 10.1023/A:1015270003717

Sykes, E. M., Innocent, T. M., Pen, I., Shuker, D. M., and West, S. A. (2008). Asymmetric larval competition in the parasitoid wasp Nasonia vitripennis: a role in sex allocation? Behav. Ecol. Sociobiol. 62, 853-854. doi: 10.1007/s00265-007-0525-9

Symonds, M. R., and Elgar, M. A. (2008). The evolution of pheromone diversity. Trends Ecol. Evol. 23, 220-228. doi: 10.1016/j.tree.2007.11.009

Tappert, L., Pokorny, T., Hofferberth, J., and Ruther, J. (2017). Sublethal doses of imidacloprid disrupt sexual communication and host finding in a parasitoid wasp. Sci. Rep. 7:42756. doi: 10.1038/srep42756

Thomas, M. L., and Simmons, L. W. (2009). Male dominance influences pheromone expression, ejaculate quality, and fertilization success in the Australian field cricket, Teleogryllus oceanicus. Behav. Ecol. 20, 1118-1124. doi: 10.1093/beheco/arp105

Tram, U., Fredrick, K., Werren, J. H., and Sullivan, W. (2006). Paternal chromosome segregation during the first mitotic division determines Wolbachia-induced cytoplasmic incompatibility phenotype. J. Cell. Sci. 119, 3655-3663. doi: $10.1242 /$ jcs.03095

Turillazzi, S., Dapporto, L., Pansolli, C., Boulay, R., Dani, F. R., Moneti, G., et al. (2006). Habitually used hibernation sites of paper wasps are marked with venom and cuticular peptides. Curr. Biol. 16, R530-R531. doi: $10.1016 /$ j.cub.2006.06.050

Turlings, T. C. J., and Erb, M. (2018). Tritrophic interactions mediated by herbivore-induced plant volatiles: mechanisms, ecological 
relevance, and application potential. Ann. Rev. Entomol. 63, 433-452. doi: 10.1146/annurev-ento-020117-043507

Unoki, S., Matsumoto, Y., and Mizunami, M. (2005). Participation of octopaminergic reward system and dopaminergic punishment system in insect olfactory learning revealed by pharmacological study. Eur. J. Neurosci. 22, 1409-1416. doi: 10.1111/j.1460-9568.2005.04318.x

Unoki, S., Matsumoto, Y., and Mizunami, M. (2006). Roles of octopaminergic and dopaminergic neurons in mediating reward and punishment signals in insect visual learning. Eur. J. Neurosci. 24, 2031-2038. doi: 10.1111/j.1460-9568.2006.05099.x

van den Assem, J. (1986). "Mating behaviour in parasitic wasps," in Insect Parasitoids, eds J. Waage and D. Greathead (London: Academic Press), 137-165.

van den Assem, J., and Beukeboom, L. W. (2004). A review of Nasonia (Chalcidoidea, Pteromalidae) courtship and mating behaviour, with some additional, new observations. Proc. Neth. Entomol. Soc. 15, 123-132.

van den Assem, J., Gijswijt, M. J., and Nübel, B. K. (1980a). Observations on courtship- and mating strategies in a few species of parasitic wasps (Chalcidoidea). Neth. J. Zool. 30, 208-227. doi: 10.1163/002829679X00386

van den Assem, J., and Jachmann, F. (1999). Changes in male perseverance in courtship and female readiness to mate in a strain of the parasitic wasp Nasonia vitripennis over a period of 20+ years. Neth. J. Zool. 49, 125-137. doi: 10.1163/156854299X00092

van den Assem, J., Jachmann, F., and de Jong, K. A. G. (1981). Courtship behaviour of Nasonia vitripennis: head nodding, mouth-part extrusion and pheromone discharge by abdomecomized males. Ent. Exp. Appl. 30, 215-218. doi: 10.1111/j.1570-7458.1981.tb03103.x

van den Assem, J., Jachmann, F., and Simbolotti, P. (1980b). Courtship behaviour of Nasonia vitripennis (Hym., Pteromalidae): some qualitative, experimental evidence for the role of pheromones. Behaviour 75, 301-307. doi: 10.1163/156853980X00456

van den Assem, J., and Vernel, C. (1979). Courtship behaviour of Nasonia vitripennis (Hym.: Pteromalidae): observations and experiments on male readiness to assume copulatory behaviour. Behaviour 68, 118-135. doi: 10.1163/156853979X00278

van den Assem, J., and Visser, J. (1976). Aspects of sexual receptivity in female Nasonia vitripennis. Biol. Behav. 1, 37-56.

van den Assem, J., and Werren, J. H. (1994). A comparison of the courtship and mating behavior of three species of Nasonia (Hymenoptera: Pteromalidae). J. Insect Behav. 7, 53-66. doi: 10.1007/BF01989827

van Dijken, M. J., van Stratum, P., and van Alphen, J. J. M. (1992). Recognition of individual-specific marked parasitized hosts by the solitary parasitoid Epidinocarcis lopezi. Behav. Ecol. Sociobiol. 30, 77-82. doi: 10.1007/BF00173943

Verhulst, E. C., Beukeboom, L. W., and van de Zande, L. (2010). Maternal control of haplodiploid sex determination in the wasp Nasonia. Science 328, 620-623. doi: $10.1126 /$ science. 1185805

Vieira, F. G., Forêt, S., He, X., Rozas, J., Field, L. M., Zhou, J.-J., et al. (2012). Unique features of odorant-binding proteins of the parasitoid wasp Nasonia vitripennis revealed by genome annotation and comparative analyses. PLoS ONE 7:e43034. doi: 10.1371 /journal.pone.0043034

Vieira, F. G., and Rozas, J. (2011). Comparative genomics of the odorantbinding and chemosensory protein gene families across the Arthropoda: origin and evolutionary history of the chemosensory system. Genome Biol. Evol. 3, 476-490. doi: 10.1093/gbe/evr033

Villet, M. H., Clitheroe, C., and Williams, K. A. (2017). The temporal occurrence of flesh flies (Diptera, Sarcophagidae) at carrion-baited traps in Grahamstown, South Africa. Afr. Invertebr. 58, 1-8. doi: 10.3897/AfrInvertebr.58.9537

Vinson, S. B. (1976). Host selection by insect parasitoids. Ann. Rev. Entomol. 21, 109-133. doi: 10.1146/annurev.en.21.010176.000545

Visser, B., Le Lann, C., den Blanken, F. J., Harvey, J. A., van Alphen, J. J., and Ellers, J. (2010). Loss of lipid synthesis as an evolutionary consequence of a parasitic lifestyle. Proc. Natl. Acad. Sci. U.S.A. 107, 8677-8682. doi: $10.1073 /$ pnas. 1001744107

Visser, B., Roelofs, D., Hahn, D. A., Teal, P. E., Mariën, J., and Ellers, J. (2012). Transcriptional changes associated with lack of lipid synthesis in parasitoids. Genome Biol. Evol. 4, 864-874. doi: 10.1093/gbe/evs065
Voss, S. C., Spafford, H., and Dadour, I. R. (2009). Annual and seasonal patterns of insect succession on decomposing remains at two locations in Western Australia. Forensic Sci. Int. 193, 26-36. doi: 10.1016/j.forsciint.2009. 08.014

Waddell, S. (2013). Reinforcement signalling in Drosophila: dopamine does it all after all. Curr. Opin. Neurobiol. 23, 324-329. doi: 10.1016/j.conb.2013.01.005

Walker, F. (1836). Monographia chalciditum. Entomologist's Monthly Magazine 3, 465-496.

Wang, X., Werren, J. H., and Clark, A. G. (2015). Genetic and epigenetic architecture of sex-biased expression in the jewel wasps Nasonia vitripennis and giraulti. Proc. Natl. Acad. Sci. U.S.A. 112, E3545-54. doi: $10.1073 /$ pnas. 1510338112

Wathes, D. C., Abayasekara, D. R., and Aitken, R. J. (2007). Polyunsaturated fatty acids in male and female reproduction. Biol. Reprod. 77, 190-201. doi: 10.1095/biolreprod.107.060558

Weiss, I., Ruther, J., and Stökl, J. (2015). Species specificity of the putative male antennal aphrodisiac pheromone in Leptopilina heterotoma, Leptopilina boulardi, and Leptopilina victoriae. Biomed Res. Int. 2015:202965. doi: 10.1155/2015/202965

Werren, J. H. (1980). Sex ratio adaptations to local mate competition in a parasitic wasp. Science 208, 1157-1159. doi: 10.1126/science.208.4448.1157

Werren, J. H. (1983). Sex ratio evolution under local mate competition in a parasitic wasp. Evolution 37, 116-124. doi: 10.1111/j.1558-5646. 1983.tb05520.x

Werren, J. H., and Loehlin, D. W. (2009). The parasitoid wasp Nasonia: an emerging model system with haploid male genetics. Cold Spring Harb. Protoc. 2009:pdb.emo134. doi: 10.1101/pdb.emo134

Werren, J. H., Richards, S., Desjardins, C. A., Niehuis, O., Gadau, J., Colbourne, J. K., et al. (2010). Functional and evolutionary insights from the genomes of three parasitoid Nasonia species. Science 327, 343-348. doi: 10.1126/science.1178028

Whiting, A. R. (1967). The biology of the parasitic wasp Mormoniella vitripennis [=Nasonia vitripennis] (Walker). Q. Rev. Biol. 42, 333-406. doi: $10.1086 / 405402$

Wibel, R. G., Cassidy, J. D., Buhse, H. E., Cummings, M. R., Bindokas, V. P., Charlesworth, J., et al. (1984). Scanning electron microscopy of antennal sense organs of Nasonia vitripennis. Trans. Am. Microsc. Soc. 103, 329-340. doi: $10.2307 / 3226468$

Wyatt, T. D. (2014). Pheromones and Animal Behavior, 2nd Edn. Cambridge: Cambridge University Press.

Wylie, H. G. (1965). Discrimination between parasitized and unparasitized house fly pupae by females of Nasonia vitripennis (Walk.) (Hymenoptera: Pteromalidae). Can. Entomol. 97, 279-286. doi: 10.4039/Ent97279-3

Xu, H., Desurmont, G., Degen, T., Zhou, G., Laplanche, D., Henryk, L., et al. (2016). Combined use of herbivore-induced plant volatiles and sex pheromones for mate location in braconid parasitoids. Plant Cell Environ. 40, 330-339. doi: $10.1111 /$ pce. 12818

$\mathrm{Xu}, \mathrm{H}$., and Turlings, T. C. J. (2018). Plant volatiles as mate-finding cues for insects. Trends Plant Sci. 23, 100-111. doi: 10.1016/j.tplants.2017.11.004

Yasui, H., Akino, T., Yasuda, T., Fukaya, M., Ono, H., and Wakamura, S. (2003). Ketone components in the contact sex pheromone of the whitespotted longicorn beetle, Anoplophora malasiaca, and pheromonal activity of synthetic ketones. Ent. Exp. Appl. 107, 167-176. doi: 10.1046/j.1570-7458. 2003.00053.x

Zahavi, A. (1975). Mate selection-a selection for a handicap. J. Theor. Biol. 53, 205-214. doi: 10.1016/0022-5193(75)90111-3

Conflict of Interest Statement: The authors declare that the research was conducted in the absence of any commercial or financial relationships that could be construed as a potential conflict of interest.

Copyright (c) 2019 Mair and Ruther. This is an open-access article distributed under the terms of the Creative Commons Attribution License (CC BY). The use, distribution or reproduction in other forums is permitted, provided the original author(s) and the copyright owner(s) are credited and that the original publication in this journal is cited, in accordance with accepted academic practice. No use, distribution or reproduction is permitted which does not comply with these terms. 